\title{
Article \\ Boosting the Catalytic Performance of Co/Mg/La Catalyst for Ammonia Synthesis by Selecting a Pre-Treatment Method
}

\author{
Hubert Ronduda ${ }^{1}{ }^{(}$, Magdalena Zybert $^{1}{ }^{\oplus}$, Wojciech Patkowski ${ }^{1}{ }^{(}$, Andrzej Ostrowski $^{1}{ }^{(}$, \\ Przemysław Jodłowski ${ }^{2} \mathbb{D}$, Damian Szymański ${ }^{3}{ }^{\oplus}$, Leszek Kępiński ${ }^{3}$ and Wioletta Raróg-Pilecka ${ }^{1, *}$ \\ 1 Faculty of Chemistry, Warsaw University of Technology, Noakowskiego 3, 00-664 Warsaw, Poland; \\ hubert.ronduda.dokt@pw.edu.pl (H.R.); magdalena.zybert@pw.edu.pl (M.Z.); \\ wpatkowski@ch.pw.edu.pl (W.P.); aostrowski@ch.pw.edu.pl (A.O.) \\ 2 Faculty of Chemical Engineering and Technology, Cracow University of Technology, Warszawska 24, \\ 31-155 Kraków, Poland; pjodlowski@pk.edu.pl \\ 3 Institute of Low Temperature and Structure Research, Polish Academy of Sciences, Okólna 2, \\ 50-950 Wrocław, Poland; d.szymanski@intibs.pl (D.S.); 1.kepinski@intibs.pl (L.K.) \\ * Correspondence: wiola@ch.pw.edu.pl; Tel.: +48-22-2345766
}

\section{check for} updates

Citation: Ronduda, H.; Zybert, M.; Patkowski, W.; Ostrowski, A.; Jodłowski, P.; Szymański, D.; Kępiński, L.; Raróg-Pilecka, W. Boosting the Catalytic Performance of $\mathrm{Co} / \mathrm{Mg} / \mathrm{La}$ Catalyst for Ammonia Synthesis by Selecting a Pre-Treatment Method. Catalysts 2021, 11,941. https://doi.org/10.3390/ catal11080941

Academic Editor: Antonio Vita

Received: 16 July 2021

Accepted: 1 August 2021

Published: 3 August 2021

Publisher's Note: MDPI stays neutral with regard to jurisdictional claims in published maps and institutional affiliations.

Copyright: (c) 2021 by the authors. Licensee MDPI, Basel, Switzerland. This article is an open access article distributed under the terms and conditions of the Creative Commons Attribution (CC BY) license (https:// creativecommons.org/licenses/by/ $4.0 /)$.

\begin{abstract}
The influence of the calcination process on the physicochemical properties and catalytic behavior of the $\mathrm{Co} / \mathrm{Mg} / \mathrm{La}$ catalysts for ammonia synthesis has been investigated. The catalysts were prepared using the different thermal pre-treatment methods prior to the activation, i.e., drying and calcination, and the respective activities for ammonia synthesis were assessed. It was found out that changing from air calcination prior to activation to direct activation of the co-precipitated species led to the different catalytic performances. The most favorable catalytic performance was achieved with $\mathrm{Co} / \mathrm{Mg} / \mathrm{La}$ prepared by calcination in air. Detailed characterization methods, employing e.g., XRPD, $\mathrm{H}_{2}$-TPD, $\mathrm{N}_{2}$-TPD, $\mathrm{CO}_{2}$-TPD, SEM, and TEM, showed that the superior catalytic behavior of this catalyst was attributed to its strong basicity and favorable adsorption properties toward hydrogen and nitrogen.
\end{abstract}

Keywords: cobalt catalyst; co-precipitation; calcination; ammonia synthesis

\section{Introduction}

Heterogeneous catalysts can be included in the group of ceramic materials defined as inorganic non-metallic solids, and along with many functional materials such as engine components, coatings, cutting tools, or bioceramics can be classified as so-called advanced ceramics [1]. It is estimated that $90 \%$ of the industrial chemical processes are based on catalysis. The size of the global catalyst market was valued at USD 34 billion in 2019 and is still growing. Thus, the development of new catalytic systems and the improvement of the existing ones are of great interest nowadays. Heterogeneous catalysis and ceramics overlap in a solid-state inorganic chemistry. Ceramics can be used in catalysis either directly as a catalyst or indirectly as a catalyst support, ensuring favorable textural properties, a dispersion of an active phase, and an appropriate mechanical and thermal resistance [1]. However, the development of ceramics as effective catalysts or catalyst supports requires the selection of appropriate compounds and, more importantly, the modification of physicochemical properties and chemical reactivity of their surfaces to adjust the interaction with adsorbed specific reactants of selected processes.

Since ammonia is one of the starting materials for the synthesis of many value-added chemicals, its synthesis is considered as one of the most important processes of the inorganic chemical industry all over the world. Globally, over $80 \%$ of ammonia produced is used for fertilizers, either for a direct application or converted to a variety of solid and liquid fertilizers, which are essential for a global food supply chain. Commonly, ammonia is synthesized via the Haber-Bosch process under high temperatures $\left(>450^{\circ} \mathrm{C}\right)$ and pressures 
(>20 MPa) over a Fe-based catalyst [2-8]. These harsh reaction conditions make the $\mathrm{NH}_{3}$ synthesis process a major consumer of energy, accounting for more than $1 \%$ of global energy consumption [2-5]. In order to overcome these limitations, many researchers are still making efforts to develop a new efficient catalyst, which shows high activity under mild reaction conditions. Over the last decades, the Ru-based catalysts supported on carbon, nitrides, zeolites, perovskites, and rare earth oxides have been developed for ammonia synthesis [2,3,9-20]. Despite the superior performance under mild conditions, the high Ru price and poor stability of Ru nanoparticles due to easy sintering limits the industrial application of these catalysts. As an alternative, the use of cobalt as the active metal component of the catalysts for ammonia synthesis appears to be promising because of its higher activity under milder pressure and temperature reaction conditions compared to that of iron-based catalysts. Recently, we have revealed that the Ba-promoted Co supported on magnesium-lanthanum mixed oxide is an efficient catalyst for $\mathrm{NH}_{3}$ synthesis [21,22]. Its high activity, i.e., from two to five times higher than that of the Fe-based catalyst (depending on the reaction conditions) was followed by the stable performance. Therefore, the cobalt catalysts can be used as a complement of the iron catalysts, and thus, the study about cobalt catalysts in $\mathrm{NH}_{3}$ synthesis attracts significant attention nowadays [21-23].

There is a general consensus that the preparation method, synthesis parameters, thermal pre-treatment conditions, and support type exert an influence on the catalytic performance of Co-supported systems. It has been reported that the direct reduction of coprecipitated $\mathrm{Co} / \mathrm{Ba}$ precursor, i.e., the respective carbonates resulted in higher reaction rates of ammonia synthesis than those obtained over the catalyst prepared from the reduction of air calcined precursor [24]. The study demonstrated that a conventional air calcination prior to activation favors the surface enrichment with barium during the reduction process. As a result, the surface Co atoms were partially covered with barium ions, leading to lower Co active sites densities. These characteristics were considered to play a detrimental role in the ammonia synthesis performance of the calcined $\mathrm{Co} / \mathrm{Ba}$ catalyst. The complexity of the air calcination and a large number of factors affecting this process raise the question of the reasonability of changing from a typical calcination prior reduction to a direct reduction of co-precipitated species, expected results of this change, and its influence on the activity of the Co catalysts for ammonia synthesis.

In this work, we have studied the reaction of ammonia synthesis on the co-precipitated $\mathrm{Co} / \mathrm{Mg} / \mathrm{La}$ catalysts prepared with two different thermal pre-treatment methods, i.e., drying and air calcination prior to the activation in hydrogen. The aim was to relate the catalytic activity with the physicochemical properties of the co-precipitated $\mathrm{Co} / \mathrm{Mg} / \mathrm{La}$ catalysts differing by the thermal pre-treatment method.

\section{Results and Discussion}

\subsection{Evaluation of the Catalytic Performance}

Table $\mathrm{S} 1$ shows the activity in $\mathrm{NH}_{3}$ synthesis of the $\mathrm{Co} / \mathrm{Mg} / \mathrm{La}$ catalysts differing by a thermal pre-treatment method. At all the tested temperatures $\left(400,430\right.$, and $\left.470{ }^{\circ} \mathrm{C}\right)$ the $\mathrm{NH}_{3}$ production rates and $\mathrm{H}_{2}$ conversions obtained over the calcined $\mathrm{Co} / \mathrm{Mg} / \mathrm{La}$ catalyst were over twice that of the non-calcined $\mathrm{Co} / \mathrm{Mg} / \mathrm{La}$ catalyst. It is noteworthy to point out that with the increase of reaction temperature, the differences in the catalytic performances of $\mathrm{Co} / \mathrm{Mg} / \mathrm{La}$ catalysts were more pronounced. The results indicate that calcination prior to hydrogen activation can improve the catalytic activity of the $\mathrm{Co} / \mathrm{Mg} / \mathrm{La}$ catalyst for ammonia synthesis. The thermal stability is another important factor to evaluate the catalyst properties. The thermal stability tests of the $\mathrm{Co} / \mathrm{Mg} / \mathrm{La}$ catalysts are shown in Figure 1 . During the $72 \mathrm{~h}$ overheating at $600{ }^{\circ} \mathrm{C}$, the catalytic activities of $\mathrm{Co} / \mathrm{Mg} / \mathrm{La}$ were stable, which indicates their excellent thermal resistance.

To understand why the $\mathrm{NH}_{3}$ production rate was higher over calcined $\mathrm{Co} / \mathrm{Mg} / \mathrm{La}$ than that achieved with non-calcined $\mathrm{Co} / \mathrm{Mg} / \mathrm{La}$, we undertook the detailed studies to identify the phenomena occurring during the calcination of the co-precipitated cobalt, magnesium, and lanthanum species. 


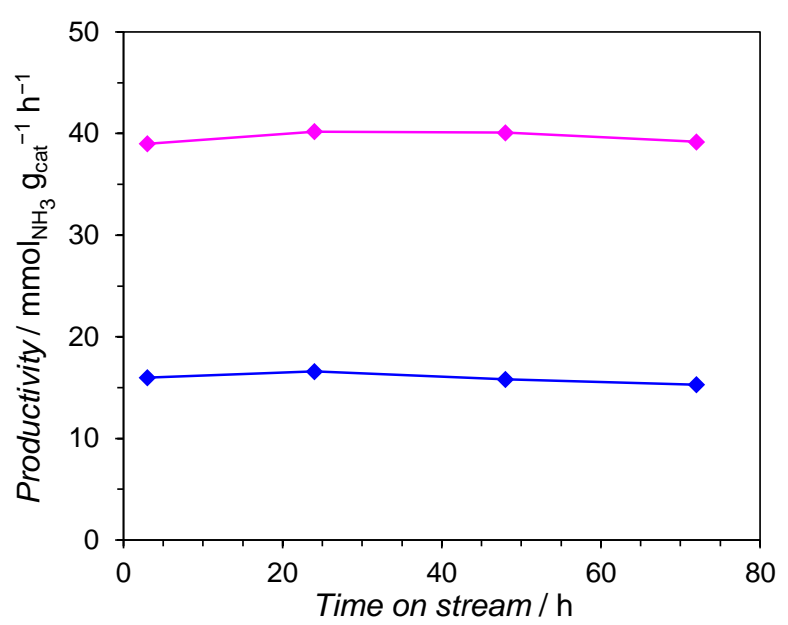

Figure 1. Time of stream performance of the calcined (-) and non-calcined (-) $\mathrm{Co} / \mathrm{Mg} / \mathrm{La}$ catalysts (measurements conditions: $470{ }^{\circ} \mathrm{C}, 6.3 \mathrm{MPa}, \mathrm{H}_{2} / \mathrm{N}_{2}=3,70 \mathrm{dm}^{3} \mathrm{~h}^{-1}$; overheating conditions: $600{ }^{\circ} \mathrm{C}, 0.1 \mathrm{MPa}, \mathrm{H}_{2} / \mathrm{N}_{2}=3,30 \mathrm{dm}^{3} \mathrm{~h}^{-1}$ ).

\section{2. $\mathrm{N}_{2}$ Physisorption}

Figure $\mathrm{S} 1$ shows the $\mathrm{N}_{2}$ adsorption-desorption isotherms and pore size distributions of the precursors and reduced catalysts differing by the thermal pre-treatment method. Both the $\mathrm{Co} / \mathrm{Mg} / \mathrm{La}$ precursors were characterized by the type IV of nitrogen adsorptiondesorption isotherm with an $\mathrm{H} 3$ hysteresis loop, which is typical for the materials with pores of widths in the range of 2-50 $\mathrm{nm}$ [25]. It corresponds to the presence of pores formed from non-parallel planes characteristic for the materials of plate-like structure. The non-calcined $\mathrm{Co} / \mathrm{Mg} / \mathrm{La}$ precursor exhibited a unimodal pore size distribution with a dominant pore size of $6 \mathrm{~nm}$. After air calcination, the shape of $\mathrm{N}_{2}$ adsorption-desorption isotherm of the respective calcined $\mathrm{Co} / \mathrm{Mg} / \mathrm{La}$ precursor changed. This indicates changes in its porous structure, as confirmed by the bimodal pore size distribution with a dominant pore size of 3 and $25 \mathrm{~nm}$. After the hydrogen activation, no differences in the shape of $\mathrm{N}_{2}$ adsorption-desorption isotherms and hysteresis loops for both the $\mathrm{Co} / \mathrm{Mg} / \mathrm{La}$ catalysts were observed (Figure S1). The bimodal pore size distributions with dominant pore sizes of 3 and $15 \mathrm{~nm}$, and 3 and $30 \mathrm{~nm}$ for the non-calcined and calcined $\mathrm{Co} / \mathrm{Mg} / \mathrm{La}$ were reported, respectively.

The texture properties of both the precursors and reduced catalysts are summarized in Table 1. Both the Co/Mg/La precursors had a similar BET surface area, ca. $30 \mathrm{~m}^{2} \mathrm{~g}^{-1}$, while a ca. 2-fold increase in the total pore volume $\left(V_{p}\right)$ and average pore diameter $(\Phi)$ for the calcined precursor was reported. An increase in the $V_{p}$ and $\Phi$ after calcination would be expected due to a loss in mass. Air calcination is a typical thermal pre-treatment method to convert e.g., precipitated hydroxide carbonates to respective oxides and remove $\mathrm{CO}_{2}$ and $\mathrm{H}_{2} \mathrm{O}$. These gases act as pore-forming agents and induce the formation of large pores. After the hydrogen activation, the differences in the textural parameters were observed (Table 1). For the non-calcined $\mathrm{Co} / \mathrm{Mg} / \mathrm{La}$ catalyst, the $\mathrm{S}_{\mathrm{BET}}$ and $\Phi$ increased 2-fold, while the $V_{p}$ increased 3-fold in comparison to the values measured for the respective precursor. The increase in the $S_{\mathrm{BET}}, \mathrm{V}_{\mathrm{p}}$, and $\Phi$ after the hydrogen activation was due to the thermal decomposition of the co-precipitated carbonates/hydroxides, and the reduction of Co species to metallic Co during the reduction process. Thus, the $\mathrm{CO}_{2}$ and $\mathrm{H}_{2} \mathrm{O}$ molecules released upon the reduction process acted as pore forming agents, leading to the higher surface area and porosity of the non-calcined catalyst. On the other hand, the BET surface area for the calcined $\mathrm{Co} / \mathrm{Mg} / \mathrm{La}$ was lower (ca. $7 \%$ ) in comparison to the respective precursor. The observed decrease of $\mathrm{S}_{\mathrm{BET}}$ suggests the agglomeration and/or aggregation of the catalyst particles during the reduction treatment. It is noteworthy that the noncalcined $\mathrm{Co} / \mathrm{Mg} / \mathrm{La}$ catalyst had the highest BET surface area, twice that of the calcined $\mathrm{Co} / \mathrm{Mg} / \mathrm{La}$ catalyst. This implies that the changing from the air calcination method prior 
to activation to the direct reduction technique would lead to improvement of the textural properties of the catalyst.

Table 1. Physicochemical properties of the $\mathrm{Co} / \mathrm{Mg} / \mathrm{La}$ catalysts.

\begin{tabular}{|c|c|c|c|c|c|c|}
\hline Catalyst & $\begin{array}{c}\text { Co Content } \\
(w t \%)\end{array}$ & $\begin{array}{c}\mathrm{S}_{\mathrm{BET}}{ }^{2} \\
\left(\mathrm{~m}^{2} \mathrm{~g}^{-1}\right)\end{array}$ & $\begin{array}{c}V_{p^{3}} \\
\left(\mathrm{~cm}^{3} \mathrm{~g}^{-1}\right)\end{array}$ & $\begin{array}{c}\Phi^{4} \\
(\mathrm{~nm})\end{array}$ & $\begin{array}{l}\text { Number of Basic } \\
\text { Sites }\left(\mu \mathrm{mol} \mathrm{g}^{-1}\right)\end{array}$ & $\begin{array}{c}\text { Density of Basic } \\
\text { Sites }^{6}\left(\mu \mathrm{mol} \mathrm{m}^{-2}\right)\end{array}$ \\
\hline $\begin{array}{c}\text { non-calcined } \\
\mathrm{Co} / \mathrm{Mg} / \mathrm{La}\end{array}$ & 9.9 & $\begin{array}{c}30.7 \\
(60.4)^{5}\end{array}$ & $\begin{array}{c}0.11 \\
(0.31)^{5}\end{array}$ & $\begin{array}{c}7.4 \\
(14.6)^{5}\end{array}$ & 346 & 5.7 \\
\hline $\begin{array}{c}\text { calcined } \\
\mathrm{Co} / \mathrm{Mg} / \mathrm{La}\end{array}$ & 10.2 & $\begin{array}{c}31.4 \\
(29.1)^{5}\end{array}$ & $\begin{array}{c}0.20 \\
(0.27)^{5}\end{array}$ & $\begin{array}{c}18.2 \\
(27.2)^{5}\end{array}$ & 352 & 12.1 \\
\hline
\end{tabular}

${ }^{1}$ Determined by using the ICP-OES and $\mathrm{H}_{2}$-TPR methods for the catalysts in the reduced form. ${ }^{2} \mathrm{~S}_{\mathrm{BET}}$, specific surface area estimated based on the BET isotherm model. ${ }^{3} \mathrm{~V}_{\mathrm{p}}$, total pore volume estimated based on the BJH isotherm model. ${ }^{4} \Phi$, average pore diameter estimated based on the BJH isotherm model. ${ }^{5}$ The $\mathrm{S}_{\mathrm{BET}}, \mathrm{V}_{\mathrm{p}}$, and $\Phi$ determined after the hydrogen activation. ${ }^{6}$ Estimated by using the amount of $\mathrm{CO}_{2}$ desorbed and BET area of the catalysts after the hydrogen activation.

\subsection{XRPD}

Figure 2a presents the XRPD patterns of the $\mathrm{Co} / \mathrm{Mg} / \mathrm{La}$ precursors differing by the thermal pre-treatment method. The non-calcined $\mathrm{Co} / \mathrm{Mg} / \mathrm{La}$ precursor consisted of two phases, i.e., orthorhombic $\mathrm{LaCO}_{3} \mathrm{OH}$ (PDF\# 49-0981) and $\mathrm{Mg}(\mathrm{OH})_{2}$ (PDF\# 44-1482). The absence of reflections from Co-bearing phases implies their presence in the amorphous forms and/or highly dispersed. After air calcination of the dried precursor, the phase composition of the respective calcined precursor was modified. In the diffraction pattern of the calcined $\mathrm{Co} / \mathrm{Mg} / \mathrm{La}$ precursor, the observed reflections were ascribed to $\mathrm{La}_{2} \mathrm{O}_{2} \mathrm{CO}_{3}$ phases crystallizing in two polymorphs: hexagonal (II type, PDF\# 37-0804) and monoclinic (Ia type, PDF\# 48-1113). The reflections of MgO (PDF\# 04-0829) were also detected. The presence of these phases was a result of the thermal decomposition of lanthanum carbonate hydroxide and magnesium hydroxide during the calcination process. The crystallite sizes of the respective phases are shown in Table S2. Interestingly, the average crystallite size of the hexagonal polymorph of $\mathrm{La}_{2} \mathrm{O}_{2} \mathrm{CO}_{3}$ was significantly larger than the monoclinic one. Figure $2 \mathrm{~b}$ shows the XRPD patterns of the $\mathrm{Co} / \mathrm{Mg} / \mathrm{La}$ after the hydrogen treatment. It was observed that after the hydrogen activation at $550{ }^{\circ} \mathrm{C}$ for $18 \mathrm{~h}$, the reflections corresponding to $\mathrm{MgO}$ (PDF\# 04-0829) and hexagonal lanthanum oxide (PDF\# 74-1144) were detected. The presence of $\mathrm{La}_{2} \mathrm{O}_{3}$ was a result of the thermal decomposition of $\mathrm{LaCO}_{3} \mathrm{OH}$ and $\mathrm{La}_{2} \mathrm{O}_{2} \mathrm{CO}_{3}$ for non-calcined and calcined $\mathrm{Co} / \mathrm{Mg} / \mathrm{La}$, respectively. Despite the same phase composition of the $\mathrm{Co} / \mathrm{Mg} / \mathrm{La}$ catalysts, the differences in the average crystallite sizes of $\mathrm{MgO}$ and $\mathrm{La}_{2} \mathrm{O}_{3}$ were observed. $\mathrm{MgO}$ crystallites had nearly the same sizes, ca. $10 \mathrm{~nm}$, while the crystallite sizes of $\mathrm{La}_{2} \mathrm{O}_{3}$ differed, i.e., 31 and $40 \mathrm{~nm}$ for the non-calcined and calcined $\mathrm{Co} / \mathrm{Mg} / \mathrm{La}$, respectively (Table S2). The observed differences were due to particles sintering during the calcination. As for the $\mathrm{Co} / \mathrm{Mg} / \mathrm{La}$ precursors, no reflections from the metallic Co and/or Co-bearing phases for the reduced catalysts were detected.

\subsection{DRIFTS}

Figure 3a depicts the DRIFTS spectra of the $\mathrm{Co} / \mathrm{Mg} / \mathrm{La}$ precursors differing by the thermal pre-treatment method. Both the $\mathrm{Co} / \mathrm{Mg} / \mathrm{La}$ precursors displayed a similar shape of DRIFTS spectra. The bands at 3776 and $3765 \mathrm{~cm}^{-1}$ were ascribed to a vibrational absorption band of bound hydroxyl groups. A broad band observed in the frequency region of $3600-3200 \mathrm{~cm}^{-1}$ corresponded to the $\mathrm{OH}$-stretching vibrations of the adsorbed water molecules, while this at $1579 \mathrm{~cm}^{-1}$ was attributed to their bending mode [26-28]. The several bands at $1454,1394,876,820$, and $750 \mathrm{~cm}^{-1}$ were attributed to $\mathrm{CO}_{3}{ }^{2-}$ groups of hydrous and/or anhydrous lanthanum carbonates. According to [29], the bands at 1454, 876, 820 , and $750 \mathrm{~cm}^{-1}$ were attributed to the $\mathrm{CO}_{3}{ }^{2-}$ groups occurring between the $(\mathrm{LaO})_{2}{ }^{2+}$ layers, while a band at $1394 \mathrm{~cm}^{-1}$ was assigned to the polydentate carbonate. Figure $4 \mathrm{~b}$ shows the DRIFTS spectra of the $\mathrm{Co} / \mathrm{Mg} / \mathrm{La}$ catalysts after the hydrogen activation at 
$550{ }^{\circ} \mathrm{C}$ for $3 \mathrm{~h}$. Both the $\mathrm{Co} / \mathrm{Mg} / \mathrm{La}$ catalysts displayed a similar shape of DRIFTS spectra. The weak band at $3753 \mathrm{~cm}^{-1}$ and the broad band in the range $3600-3300 \mathrm{~cm}^{-1}$ were assigned to the $\mathrm{OH}$-stretching vibrations of the adsorbed water molecules and the additional bands at $1770-750 \mathrm{~cm}^{-1}$ corresponding to the $\mathrm{La}_{2} \mathrm{O}_{2} \mathrm{CO}_{3}$ species were detected. The bands that appeared at 1768 and $1728 \mathrm{~cm}^{-1}$ were associated with a $>\mathrm{C}=\mathrm{O}$ group of the $\mathrm{La}_{2} \mathrm{O}_{2} \mathrm{CO}_{3}$ species. The bands at 1478 and $1136 \mathrm{~cm}^{-1}$ were assigned to type Ia (monoclinic) $\mathrm{La}_{2} \mathrm{O}_{2} \mathrm{CO}_{3}$, while the bands at 864 and $762 \mathrm{~cm}^{-1}$ corresponded to type II (hexagonal) $\mathrm{La}_{2} \mathrm{O}_{2} \mathrm{CO}_{3}$. This implies that the thermal decomposition of carbonaceous species requires long-term heating, and even after heating for $3 \mathrm{~h}$, the decomposition was not completed. This is because $\mathrm{La}_{2} \mathrm{O}_{2} \mathrm{CO}_{3}$ is a stable intermediate in the thermal decomposition of lanthanum carbonate, $\mathrm{La}_{2}\left(\mathrm{CO}_{3}\right)_{3}$. The band observable at $1394 \mathrm{~cm}^{-1}$ was assigned to the formation of polydentate carbonate. The two bands at 2501 and $2405 \mathrm{~cm}^{-1}$ were associated with physically adsorbed $\mathrm{CO}_{2}[28,29]$.
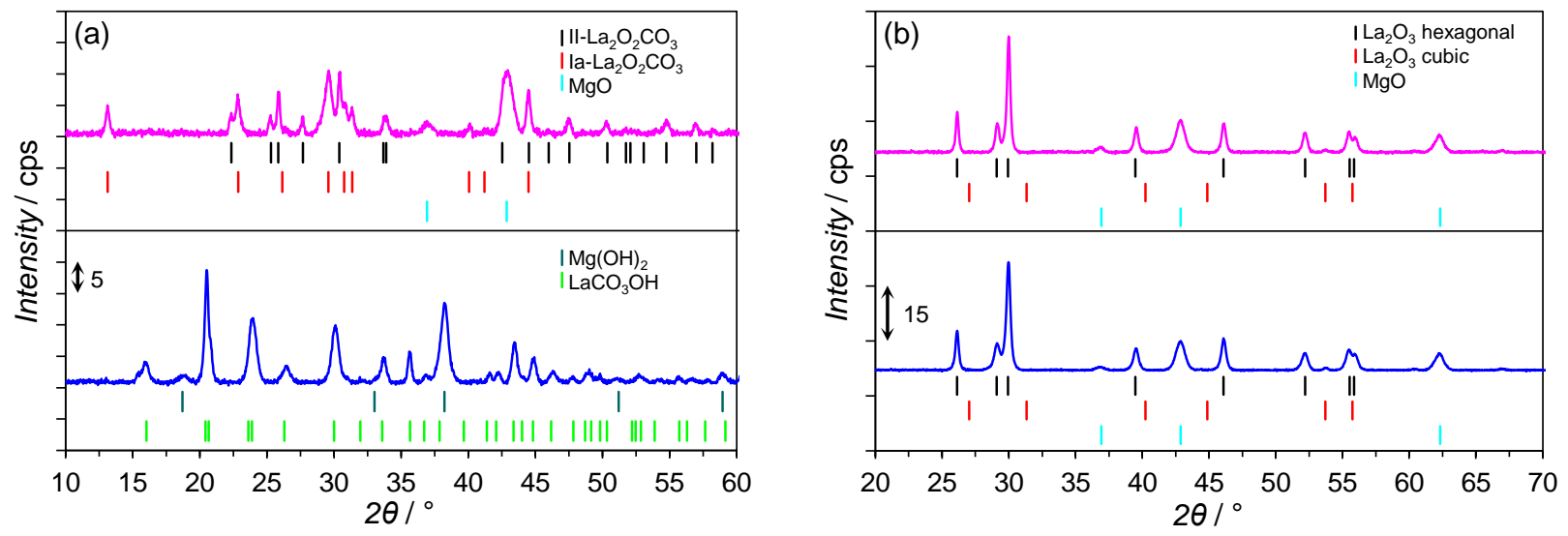

Figure 2. XRPD patterns of the calcined (-) and non-calcined (-) Co/Mg/La catalysts in: (a) the precursor and (b) the reduced forms.
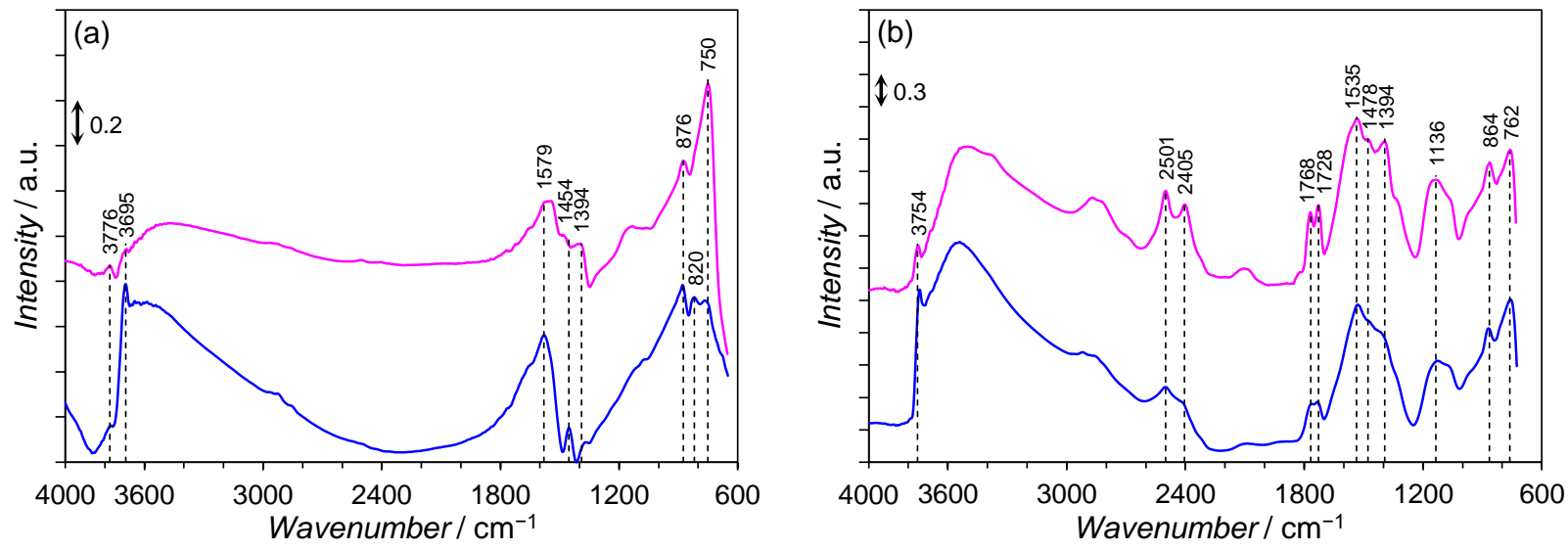

Figure 3. DRIFTS spectra of the calcined (-) and non-calcined (-) Co/Mg/La catalysts in: (a) the precursor and (b) the reduced forms.

\section{5. $\mathrm{H}_{2}-\mathrm{TPR}$}

Figure 4 shows the TG/DTA-MS profiles of the $\mathrm{Co} / \mathrm{Mg} / \mathrm{La}$ precursors differing by the thermal pre-treatment method. For the non-calcined $\mathrm{Co} / \mathrm{Mg} / \mathrm{La}$ precursor (Figure $4 \mathrm{a}$ ), a three-stage reduction process was distinguished in the temperature ranges:

(1) $\quad 30-150{ }^{\circ} \mathrm{C}$, a slight mass loss (ca. $5 \%$ ) with a maximum rate of mass loss at $98{ }^{\circ} \mathrm{C}$ was observed. This was associated with the desorption of physisorbed water and carbon dioxide, as confirmed by the signals at $\mathrm{m} / \mathrm{e}=18$ and $\mathrm{m} / \mathrm{e}=44$ in the mass spectra. 
(2) $\quad 150-500{ }^{\circ} \mathrm{C}$, a significant mass loss (ca. $25 \%$ ) with the maximum rates of mass loss at 362 and $434{ }^{\circ} \mathrm{C}$ were recorded and associated with an intense water and carbon dioxide release (the signals at $\mathrm{m} / \mathrm{e}=18$ and $\mathrm{m} / \mathrm{e}=44$ in the mass spectrum). This was attributed to the thermal decomposition of the co-precipitated cobalt hydroxy carbonate to cobalt(II,III) oxide and lanthanum hydroxy carbonate to lanthanum oxide carbonate. The signal at $\mathrm{m} / \mathrm{e}=18$ in the mass spectrum could also be attributable to the dehydroxylation of $\mathrm{Mg}(\mathrm{OH})_{2}$ occurring at ca. $350{ }^{\circ} \mathrm{C}$ [30] and the reduction of $\mathrm{Co}_{3} \mathrm{O}_{4}$ to metallic $\mathrm{Co}$, occurring typically in the temperature range of $250-450{ }^{\circ} \mathrm{C}$ [31]. Moreover, the hydrogenation of $\mathrm{CO}_{2}$ (released upon the decarboxylation of lanthanum oxide carbonate) to methane occurred. The confirmation was the appearance of the signal at $\mathrm{m} / \mathrm{e}=15$ in the mass spectrum with the maximum at $425^{\circ} \mathrm{C}$.

(3) $500-600{ }^{\circ} \mathrm{C}$, a slight mass loss (ca. $3 \%$ ) related to the thermal decomposition of $\mathrm{La}_{2} \mathrm{O}_{2} \mathrm{CO}_{3}$ with subsequent hydrogenation of $\mathrm{CO}_{2}$ to $\mathrm{CH}_{4}$ was detected. The confirmation was the signal at $\mathrm{m} / \mathrm{e}=15$ in the mass spectrum with the maximum at $551{ }^{\circ} \mathrm{C}$.
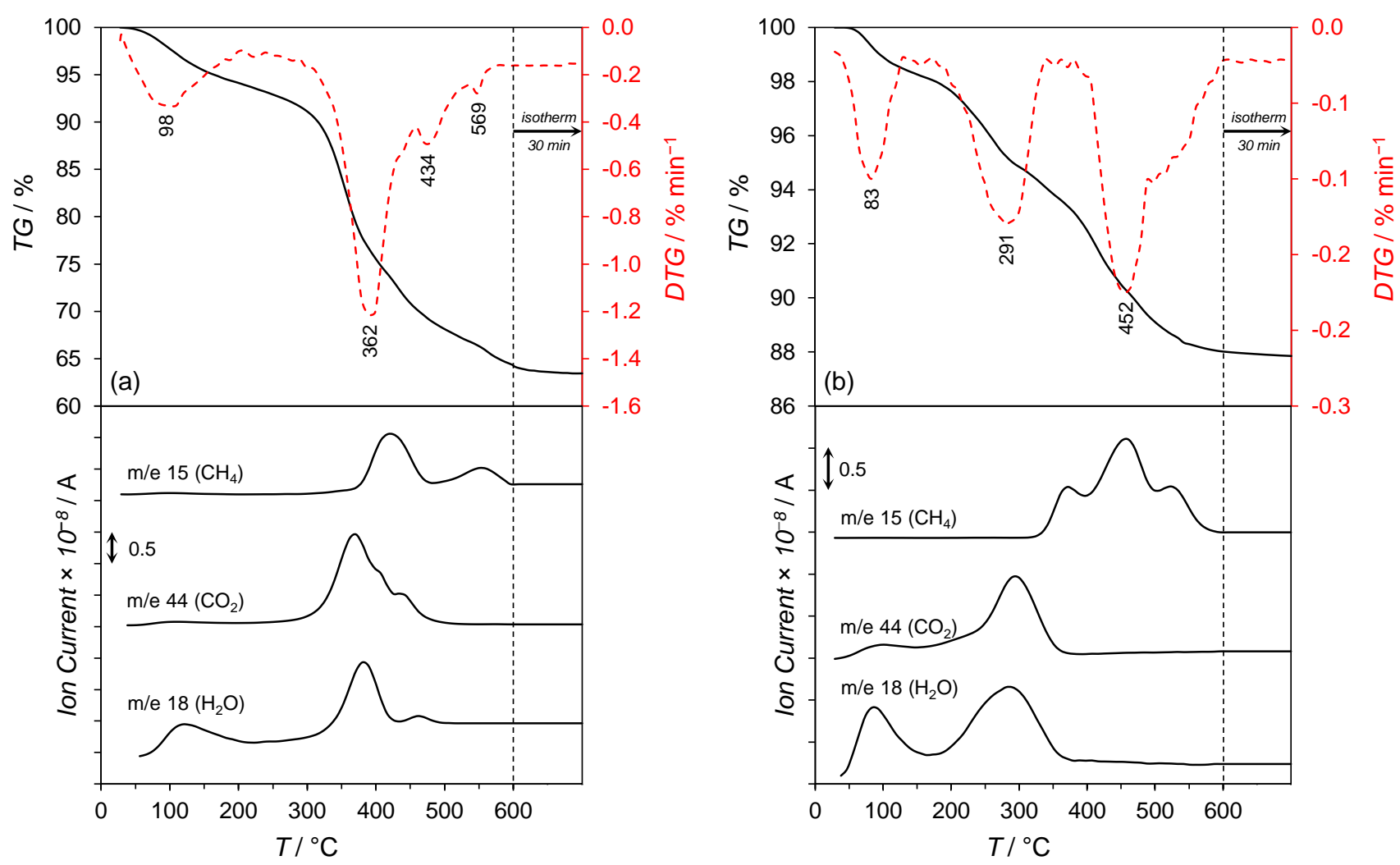

Figure 4. TG/DTA-MS profiles of: (a) the non-calcined and (b) the calcined $\mathrm{Co} / \mathrm{Mg} / \mathrm{La}$ precursors.

After air calcination of the dried precursor, the phase composition of the respective calcined precursor was modified (Figure 2a), and thus, the course of its reduction process differed (Figure $4 \mathrm{~b}$ ). The reduction process of the calcined $\mathrm{Co} / \mathrm{Mg} / \mathrm{La}$ precursor consisted of three stages in the temperature ranges:

(1) $30-150{ }^{\circ} \mathrm{C}$, a slight mass loss (ca. $2 \%$ ) with a maximum rate of mass loss at $83{ }^{\circ} \mathrm{C}$ associated with the desorption of physisorbed water and carbon dioxide was observed. The confirmation was the signals at $\mathrm{m} / \mathrm{e}=18$ and $\mathrm{m} / \mathrm{e}=44$ in the mass spectra.

(2) $\quad 150-400{ }^{\circ} \mathrm{C}$, a mass loss of ca. $4 \%$ related to the reduction of $\mathrm{Co}_{3} \mathrm{O}_{4}$ to metallic $\mathrm{Co}$ and the thermal decomposition of $\mathrm{La}_{2} \mathrm{O}_{2} \mathrm{CO}_{3}$ to $\mathrm{La}_{2} \mathrm{O}_{3}$ was detected. This was confirmed by the signals at $\mathrm{m} / \mathrm{e}=18$ and $\mathrm{m} / \mathrm{e}=44$ in the mass spectrum, respectively. The appearance of the signal at $\mathrm{m} / \mathrm{e}=15$ in the mass spectra was due to the hydrogenation of carbon dioxide (released upon the decarboxylation of $\mathrm{La}_{2} \mathrm{O}_{2} \mathrm{CO}_{3}$ ) to methane. 
(3) $\quad 400-600{ }^{\circ} \mathrm{C}$, a mass loss of ca. $6 \%$ associated with the continuous hydrogenation of carbon dioxide to methane was observable, as confirmed by the signal at $\mathrm{m} / \mathrm{e}=15 \mathrm{in}$ the mass spectrum with the maximum at $452{ }^{\circ} \mathrm{C}$.

\subsection{SEM and TEM}

Figure 5 shows the SEM and TEM micrographs of $\mathrm{Co} / \mathrm{Mg} / \mathrm{La}$ differenced by the thermal pre-treatment method. The distinct differences in the morphology of the $\mathrm{Co} / \mathrm{Mg} / \mathrm{La}$ precursors were observed both in the SEM and TEM images (Figure 5a). For the noncalcined precursor, the large particles of lanthanum carbonate hydroxide (up to $200 \mathrm{~nm}$ ) and small flake-like particles of magnesium hydroxide were observed. According to the XRPD, the average crystallite sizes of $\mathrm{LaCO}_{3} \mathrm{OH}$ and $\mathrm{Mg}(\mathrm{OH})_{2}$ were 20 and $8 \mathrm{~nm}$, respectively (Table S2). Thus, it is observable that the average crystallite size of lanthanum carbonate hydroxide was much smaller than its particle size observed in the SEM and TEM images. This suggests that the observed large particles were aggregates composed of the smaller crystallites. Note that the BET surface area of both the precursors was nearly the same, though there was a noticeable difference in the pore volume (Table 1). The reason is probably more "dense" packing of $\mathrm{LaCO}_{3} \mathrm{OH}$ crystallites in the large particles. During air calcination, these large particles of lanthanum carbonate hydroxy transformed into two polymorphs of lanthanum oxide carbonate, hexagonal, and monoclinic. The flakelike $\mathrm{Mg}(\mathrm{OH})_{2}$ transformed into irregular in shape $\mathrm{MgO}$ particles with nearly unchanged average crystallite sizes, ca. $10 \mathrm{~nm}$ (Table S2).

(a)
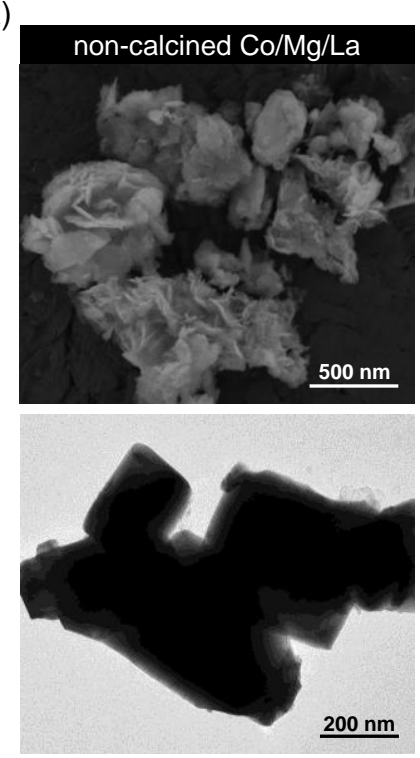
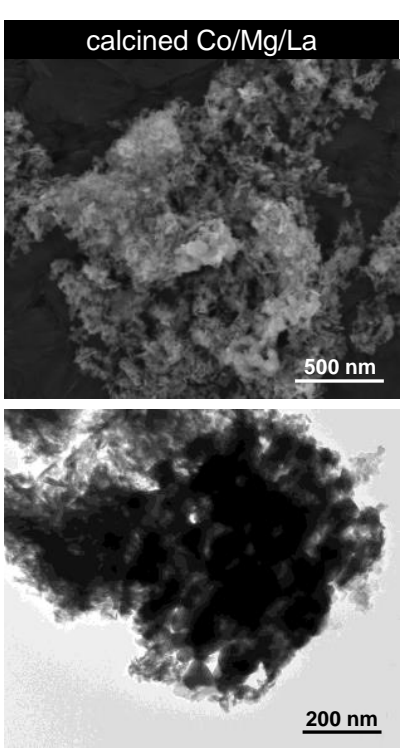

(b)
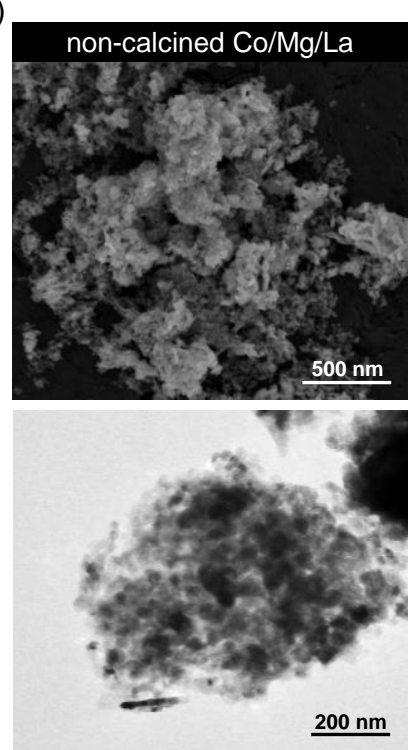
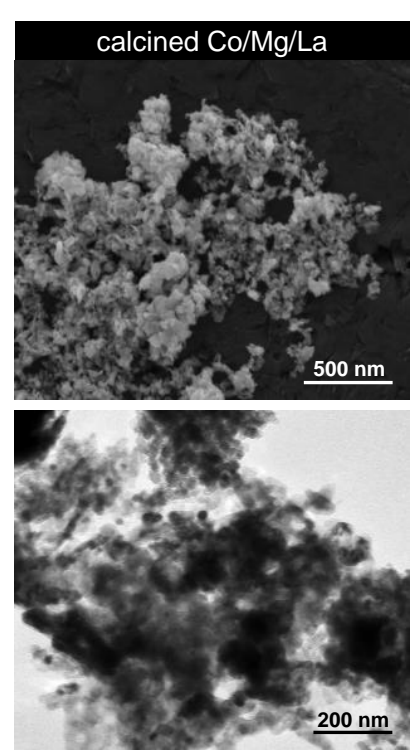

Figure 5. Representative SEM and TEM micrographs of the $\mathrm{Co} / \mathrm{Mg} / \mathrm{La}$ catalysts in: (a) the precursor and (b) the reduced forms.

Figure $5 \mathrm{~b}$ presents the SEM and TEM images of the Co/Mg/La catalysts after the hydrogen activation. Both the catalysts had similar morphology. Two fractions of the particles were observed. The larger ones, showing a higher contrast in TEM images, were lanthanum oxide, while the smaller ones, with a lower TEM contrast, were magnesium oxide. This agrees with the XRPD analysis showing the presence of $\mathrm{La}_{2} \mathrm{O}_{3}$ and $\mathrm{MgO}$ phases in both the catalysts. Note that there was a significant difference in the BET surface area between the $\mathrm{Co} / \mathrm{Mg} / \mathrm{La}$ catalysts, i.e., the $\mathrm{S}_{\mathrm{BET}}$ of the non-calcined catalyst was almost twice that of the calcined catalyst (Table 1). This result is unexpected given similar X-ray diffraction and microscopy data. A possible explanation could be a different aggregation of crystallites of phases identified in both the catalysts (more extensive in the calcined 
$\mathrm{Co} / \mathrm{Mg} / \mathrm{La}$ ). This could be due to the different mechanisms of the phase evolution of both the precursors during the reduction process.

An important issue concerning the reduced catalysts is the lack of evidence of metallic Co and/or Co-bearing phases. There were no the Co reflections in the XRPD patterns and no well-defined Co particles in the TEM images. Probably, the sizes of cobalt particles were small, and, what is more, they were at least partly oxidized after exposure to air after the reduction.

Figure 6 displays the EDS elemental mapping of $\mathrm{Co} / \mathrm{Mg} / \mathrm{La}$ in both the precursor and reduced forms differenced by the thermal pre-treatment method. The EDS elemental mapping confirmed that oxygen $(\mathrm{O})$, magnesium $(\mathrm{Mg})$, and cobalt $(\mathrm{Co})$ were rather uniformly distributed on the micrometer scale. On the contrary, lanthanum (La) showed evident inhomogeneities in both the precursor and reduced catalysts. This effect indicates that La-containing compounds formed much larger particles than those containing $\mathrm{Mg}$ and Co. A more detailed analysis of the element's distribution in the catalysts after the hydrogen activation is presented in a Supplementary Material (Figure S2 and Table S3). It confirmed the presence of large (up to $1 \mu \mathrm{m}$ ) La-containing particles. Interestingly, it appears that the concentration of cobalt is noticeably lower in the places where lanthanum prevails (especially for the non-calcined $\mathrm{Co} / \mathrm{Mg} / \mathrm{La}$ ). Thus, it can be concluded that $\mathrm{Co}$ preferentially deposits on magnesium oxide, rather than lanthanum oxide.

\section{7. $\mathrm{CO}_{2}-\mathrm{TPD}$}

Figure 7 presents the $\mathrm{CO}_{2}$-TPD profiles of the $\mathrm{Co} / \mathrm{Mg} / \mathrm{La}$ catalysts differenced by the thermal pre-treatment method. The profiles could be divided into three kinds of the basic sites at low-, medium-, and high-temperatures relating to the strength of the basic sites. $\mathrm{CO}_{2}$ desorption observed in the low-temperature region $\left(<250^{\circ} \mathrm{C}\right)$ was ascribed to the hydroxyl groups $\left(\mathrm{OH}^{-}\right)$which are capable of accepting protons serving as the Brønsted basic sites. The $\mathrm{CO}_{2}$ desorption peaks at medium- $\left(250-550{ }^{\circ} \mathrm{C}\right)$ and high- $\left(>550{ }^{\circ} \mathrm{C}\right)$ temperature regions were attributed to the various oxygen species (e.g., $\mathrm{O}_{2}{ }^{2-}, \mathrm{O}^{-}$) which are able to donate electrons serving as the Lewis basic sites. It has been reported [11,13,15,32,33] that medium and strong surface basicity results in an effective electron donation to Co atoms and subsequent electron transfer from Co d-orbitals to the antibonding $\pi^{*}$ orbitals of $\mathrm{N}_{2}$, molecule facilitating the $\mathrm{N}_{2}$ dissociation by weakening the $\mathrm{N} \equiv \mathrm{N}$ bond.

The $\mathrm{CO}_{2}$-TPD profiles recorded for the $\mathrm{Co} / \mathrm{Mg} / \mathrm{La}$ catalysts (Figure 7) revealed that the $\mathrm{CO}_{2}$ desorption peaks had similar shapes and consisted of four overlapping peaks. The desorption peaks at $116-132{ }^{\circ} \mathrm{C}$ were ascribed to the adsorbed $\mathrm{CO}_{2}$ on weak basic sites $\left(\mathrm{OH}^{-}\right.$groups) and the peaks at $254-265^{\circ} \mathrm{C}$ corresponded to the interaction of $\mathrm{CO}_{2}$ with medium basic sites of magnesium oxide $\left(\mathrm{Mg}^{2+}-\mathrm{O}^{2-}\right.$ pairs) [34]. The desorption peaks of carbon dioxide at $540-559{ }^{\circ} \mathrm{C}$ were associated with the interaction of $\mathrm{CO}_{2}$ with the hexagonal $\mathrm{La}_{2} \mathrm{O}_{3}$, while the peaks at $723-774{ }^{\circ} \mathrm{C}$ corresponded to the interaction of $\mathrm{CO}_{2}$ with the cubic $\mathrm{La}_{2} \mathrm{O}_{3}[26,28]$. Note that the strong basicity of $\mathrm{La}_{2} \mathrm{O}_{3}$ led to the formation of respective carbonates upon the $\mathrm{CO}_{2}$ exposure. Thus, $\mathrm{CO}_{2}$ desorbed at $>500{ }^{\circ} \mathrm{C}$ originated from the thermal decomposition of these carbonate species.

Based on the total desorption of $\mathrm{CO}_{2}$, the basicity of the catalysts was evaluated. No significant differences in the number of basic sites on the catalysts were observed. The differences in the density of the basic sites were more pronounced, i.e., the basic sites density on the calcined $\mathrm{Co} / \mathrm{Mg} / \mathrm{La}$ reached $12.1 \mu \mathrm{mol} \mathrm{m}{ }^{-2}$, which was two times that of the non-calcined $\mathrm{Co} / \mathrm{Mg} / \mathrm{La}\left(5.7 \mu \mathrm{mol} \mathrm{m}^{-2}\right)$. These differences were associated with the thermal pre-treatment method. Applying the typical air calcination method resulted in the crystallite growth (Table S2) and the decrease of the surface area after the hydrogen activation (Table 1). As a result, the calcined $\mathrm{Co} / \mathrm{Mg} / \mathrm{La}$ catalyst possessed such densely distributed basic sites of high electron-donation ability and made the superior performance of this catalyst for ammonia synthesis possible (Table S1 and Figure 1). 
(a)
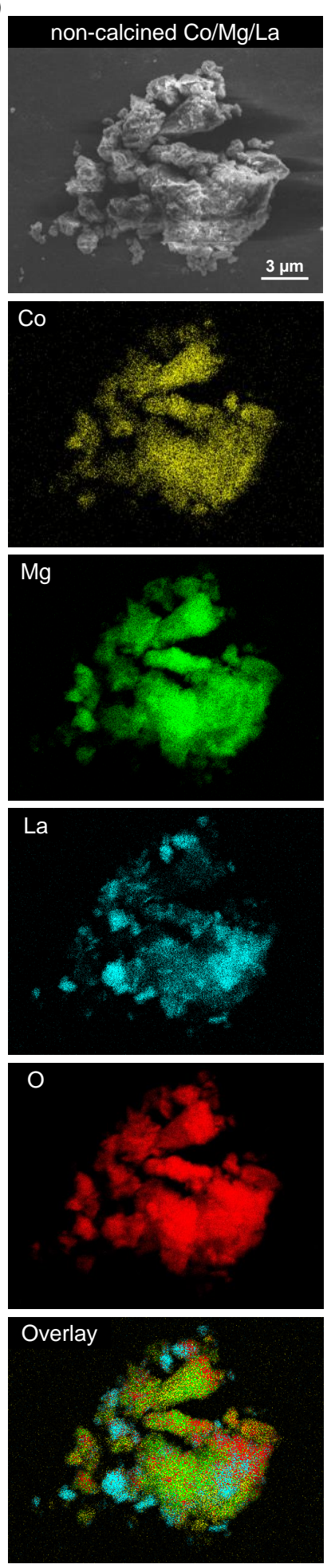
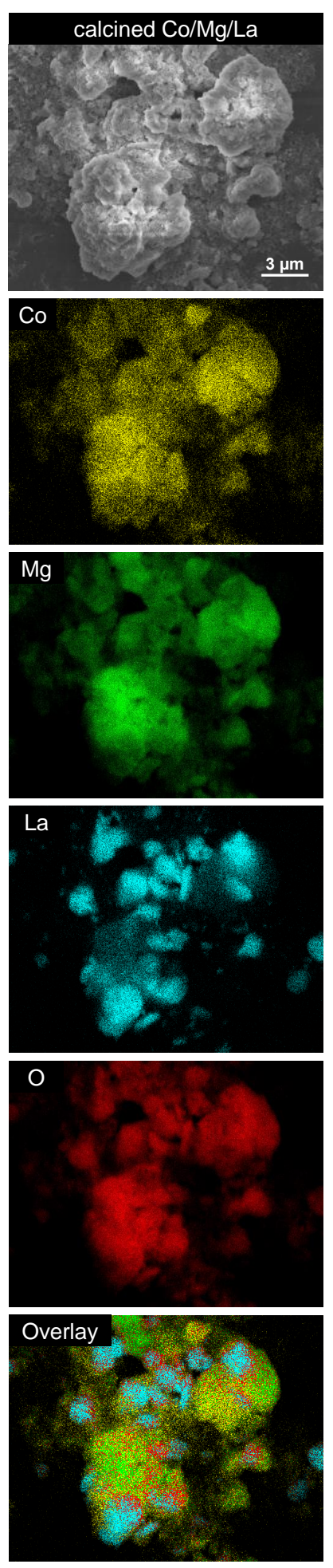

(b)
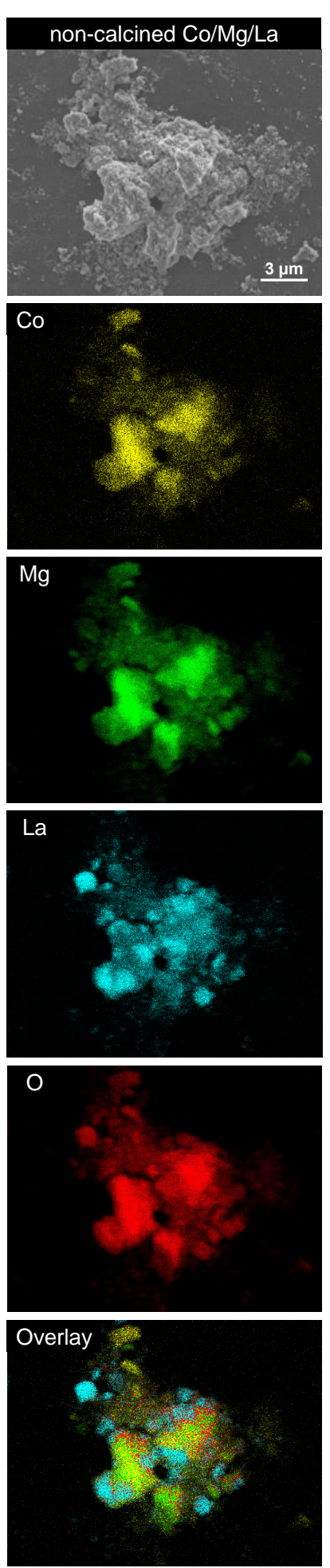
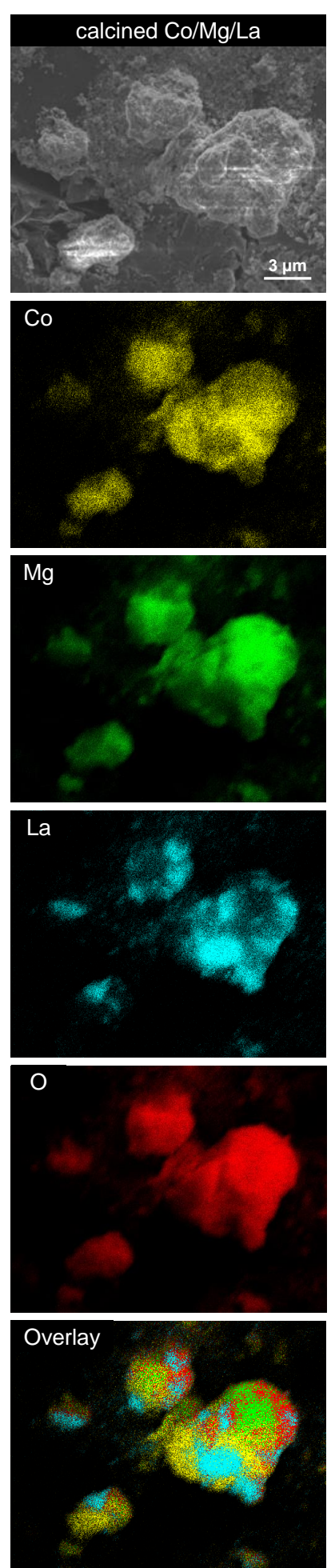

Figure 6. Representative SEM micrographs and EDS maps of the $\mathrm{Co}, \mathrm{Mg}$, La, and O elements of the $\mathrm{Co} / \mathrm{Mg} / \mathrm{La}$ catalysts in: (a) the precursor and (b) the reduced forms. 


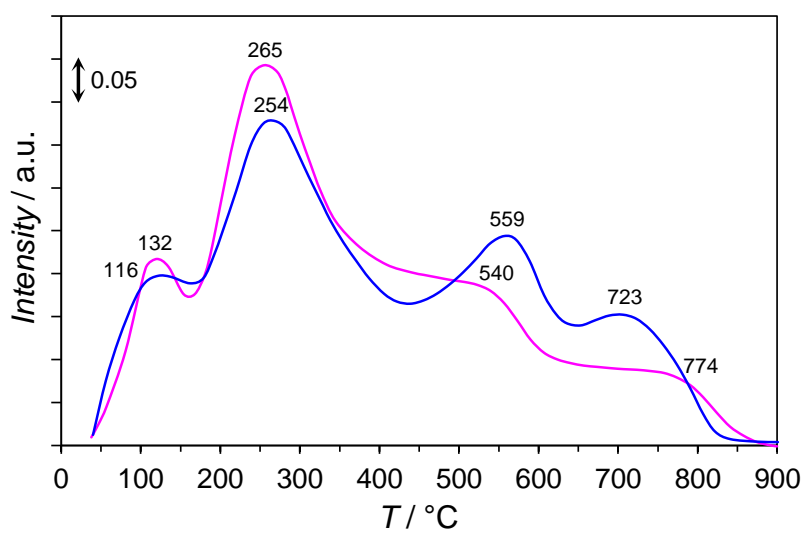

Figure 7. $\mathrm{CO}_{2}$-TPD profiles of the calcined $(-)$ and non-calcined $(-) \mathrm{Co} / \mathrm{Mg} / \mathrm{La}$ catalysts.

\section{8. $\mathrm{H}_{2}-\mathrm{TPD}$ and $\mathrm{N}_{2}-\mathrm{TPD}$}

Figure 8 shows the $\mathrm{H}_{2}$-TPD and $\mathrm{N}_{2}$-TPD profiles of the $\mathrm{Co} / \mathrm{Mg} / \mathrm{La}$ catalysts differing by the thermal pre-treatment method. In the temperature range of $50-900{ }^{\circ} \mathrm{C}$, the desorbed $\mathrm{H}_{2}$ and $\mathrm{N}_{2}$ molecules were assigned to three types of sites on the cobalt surface, which were related to the strength of the interaction between these molecules and the Co surface: desorbing below $250{ }^{\circ} \mathrm{C}$ (LT, i.e., low-temperature), desorbing between 250 and $550{ }^{\circ} \mathrm{C}$ (MT, i.e., medium-temperature) and desorbing above $550^{\circ} \mathrm{C}$ (HT, i.e., high-temperature). These were due to the desorption of hydrogen and nitrogen molecules that were weakly, intermediately, and strongly bound to the Co surface, respectively. The $\mathrm{H}_{2}$-TPD profile of non-calcined $\mathrm{Co} / \mathrm{Mg} / \mathrm{La}$ was composed of two rather symmetric hydrogen desorption peaks at 127 and $684{ }^{\circ} \mathrm{C}$, respectively. The desorption peak of $\mathrm{H}_{2}$ at $684{ }^{\circ} \mathrm{C}$ showed the largest intensity and was associated with a strong chemisorption state of $\mathrm{H}_{2}$ on the cobalt surface [5]. In addition to the hydrogen desorption peaks at $123^{\circ} \mathrm{C}$ and $429{ }^{\circ} \mathrm{C}$, the peak located at $714{ }^{\circ} \mathrm{C}$ with a shoulder at $598^{\circ} \mathrm{C}$ appeared in the $\mathrm{H}_{2}$-TPD profile of the calcined $\mathrm{Co} / \mathrm{Mg} / \mathrm{La}$. It can be concluded that the calcination prior to the activation led to the decrease of the adsorption strength on the cobalt surface for $\mathrm{H}_{2}$ chemisorption. Consequently, the area ratio of medium-temperature to high-temperature peaks (i.e., MT/HT) differed, and the highest ratio was for the calcined $\mathrm{Co} / \mathrm{Mg} / \mathrm{La}$ catalyst (Table 2), indicating the higher presence of intermediate sites on the Co surface for $\mathrm{H}_{2}$ adsorption. These results indicate that the $\mathrm{Co}$ active sites for $\mathrm{H}_{2}$ adsorption, on which $\mathrm{H}_{2}$ desorbed at a mediumtemperature range $\left(250-550{ }^{\circ} \mathrm{C}\right)$, were responsible for the synthesis of $\mathrm{NH}_{3}$. The sites at a high-temperature region $\left(>550{ }^{\circ} \mathrm{C}\right)$, on which the activation energy for $\mathrm{H}_{2}$ desorption was high, were not involved in the synthesis of $\mathrm{NH}_{3}$ (under the reaction conditions, i.e., at temperatures of $400-470{ }^{\circ} \mathrm{C}$ ). As a result, the dissociative adsorption of nitrogen on the Co active sites was suppressed to some extent, and consequently, so was the activity of the catalyst $[35,36]$. As revealed in Table 2, ca. $71 \%$ of the active sites on the non-calcined $\mathrm{Co} / \mathrm{Mg} / \mathrm{La}$ catalyst were occupied by hydrogen atoms in the strong chemisorption state in comparison to ca. $57 \%$ that of calcined $\mathrm{Co} / \mathrm{Mg} / \mathrm{La}$. This result clearly revealed that a higher number of $\mathrm{Co}$ surface atoms were available for $\mathrm{NH}_{3}$ synthesis under the reaction conditions over the calcined catalyst.

Table 2. $\mathrm{H}_{2}$-TPD data of the $\mathrm{Co} / \mathrm{Mg} / \mathrm{La}$ catalysts.

\begin{tabular}{|c|c|c|c|c|c|c|c|}
\hline \multirow{2}{*}{ Catalyst } & \multicolumn{4}{|c|}{$\mathrm{H}_{2}$ Desorbed $^{1}\left(\mu \mathrm{mol} \mathrm{g}^{-1}\right)$} & \multirow{2}{*}{ MT/HT 2 (一) } & \multirow{2}{*}{$\mathrm{FE}^{3}(\%)$} & \multirow{2}{*}{$\mathrm{d}_{\mathrm{H}_{2}}{ }^{4}(\mathrm{~nm})$} \\
\hline & LT & MT & HT & Total & & & \\
\hline non-calcined $\mathrm{Co} / \mathrm{Mg} / \mathrm{La}$ & 7.2 & 17.4 & 59.3 & 83.9 & 0.29 & 16.2 & 7.8 \\
\hline calcined $\mathrm{Co} / \mathrm{Mg} / \mathrm{La}$ & 11.9 & 27.1 & 52.2 & 91.1 & 0.52 & 11.7 & 10.8 \\
\hline
\end{tabular}

${ }^{1} \mathrm{LT}, \mathrm{MT}, \mathrm{HT}$, the types of sites on the Co surface calculated by integration the area under the peak in the temperature range of $<250{ }^{\circ} \mathrm{C}(\mathrm{LT})$, $250-550{ }^{\circ} \mathrm{C}(\mathrm{MT})$, and $>550{ }^{\circ} \mathrm{C}(\mathrm{HT}) .{ }^{2}$ The area ratio of the medium-temperature (MT) and high-temperature $(\mathrm{HT})$ peaks. ${ }^{3} \mathrm{FE}$, fraction exposed calculated based on the number of surface Co atoms and the total number of Co atoms in the sample. ${ }^{4} \mathrm{~d}_{\mathrm{H}_{2}}$, average cobalt particle size calculated based on FE. 


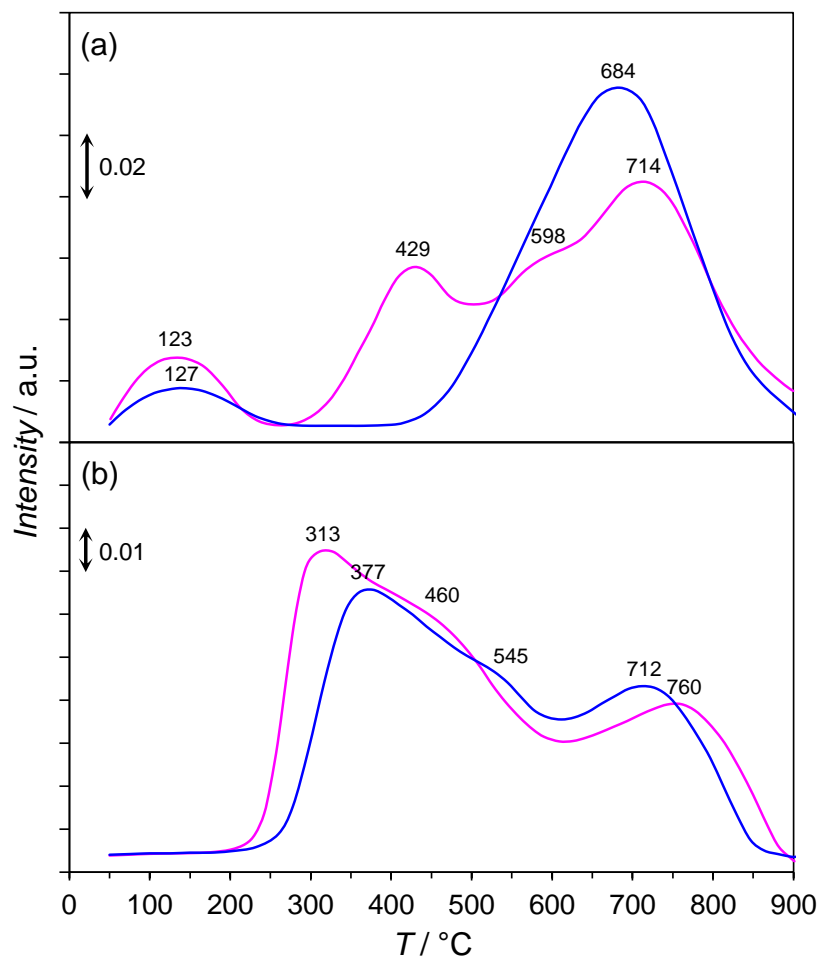

Figure 8. (a) $\mathrm{H}_{2}$-TPD and (b) $\mathrm{N}_{2}$-TPD profiles of the calcined ( - ) and non-calcined $(-)$ $\mathrm{Co} / \mathrm{Mg} / \mathrm{La}$ catalysts.

The $\mathrm{N}_{2}$-TPD profiles recorded for the $\mathrm{Co} / \mathrm{Mg} / \mathrm{La}$ catalysts revealed that the desorption profiles of $\mathrm{N}_{2}$ had a similar shape and consisted of the medium-temperature peak at 313-377 ${ }^{\circ} \mathrm{C}$ with a shoulder at $460-545^{\circ} \mathrm{C}$ and high-temperature peak at $712-760{ }^{\circ} \mathrm{C}$. The broad and asymmetric shapes of the medium-temperature peaks were presumably due to the readsorption of desorbed nitrogen molecules within a catalyst bed [37-39]. According to Hinrichsen et al. [38,39], a readsorption of $\mathrm{N}_{2}$ gives rise to an asymmetric peak broadening to the higher temperatures because of the delayed elution of the desorbed nitrogen molecules. The origin of the high-temperature peaks above $700{ }^{\circ} \mathrm{C}$ is not clear. Taking into account the weak binding strength between the nitrogen molecules and cobalt, the equilibrium coverages of $\mathrm{N}_{2}$ on the Co surfaces, in particular, at high temperatures $\left(>550{ }^{\circ} \mathrm{C}\right.$ ) will be modest [40]. Therefore, it seems reasonable to suggest that $\mathrm{N}_{2}$ desorbing at the high temperatures did not desorb from the cobalt surfaces. Possibilities could be that $\mathrm{N}_{2}$ desorbed from the formed new bulk and surface phases partly incorporated nitrogen atoms into the interstitial positions of the cobalt crystal lattice or led to the internal diffusion of $\mathrm{N}_{2}$ within a porous material [41,42]. Assuming that the desorption of $\mathrm{N}_{2}$ from the Co surfaces occurred in the medium-temperature range, the rough estimation of the $\mathrm{N}_{2}$ molecules desorbed was made by integrating the area under the peak to maximum at 313 and $377^{\circ} \mathrm{C}$, respectively, and multiplying by 2 . The results of this procedure were 26.3 and $27.2 \mu \mathrm{mol} \mathrm{g}{ }^{-1}$ of nitrogen desorbed for the non-calcined and calcined $\mathrm{Co} / \mathrm{Mg} / \mathrm{La}$ catalysts, respectively. This corresponded to the 52.4 and $54.4 \mu \mathrm{mol} \mathrm{g}^{-1}$ active sites assuming a stoichiometry of $1 / 1$ for $\mathrm{N}^{*}\left({ }^{*}\right.$, active site). Based on the number of cobalt surface atoms determined by $\mathrm{H}_{2}$-TPD (Table 2), the number of $\mathrm{N}^{*}$ corresponded to the coverage of $\Theta_{\mathrm{N}}=0.31$ and $\Theta_{\mathrm{N}}=0.30$ for the non-calcined and calcined $\mathrm{Co} / \mathrm{Mg} / \mathrm{La}$, respectively. This is in good accordance with the saturation coverage of $\Theta_{\mathrm{N}} \max =0.33$ observed e.g., on the FCC Co(111) surface [40].

Note that the $\mathrm{H}_{2}$ and $\mathrm{N}_{2}$ molecules competed for the Co active sites on the calcined $\mathrm{Co} / \mathrm{Mg} / \mathrm{La}$ catalyst, which was observed by the corresponding desorption peaks of these molecules in the medium-temperature range, i.e., $250-550{ }^{\circ} \mathrm{C}$ (Figure 8 ). It has been reported [5] that the presence of the active sites for chemisorption of $\mathrm{H}_{2}$ and $\mathrm{N}_{2}$, in which 
the activation energy for their desorption is comparable, is superior in the terms of activity in $\mathrm{NH}_{3}$ synthesis. This is due to suppressing the inhibition of $\mathrm{NH}_{3}$ production rate by the hydrogen and nitrogen molecules themselves. These results suggest that the enhancement of the performance of the calcined $\mathrm{Co} / \mathrm{Mg} / \mathrm{La}$ catalyst for ammonia synthesis could also be attributable to the high number $\mathrm{Co}$ active sites available for ammonia synthesis under reaction conditions and the competitive adsorption of the $\mathrm{H}_{2}$ and $\mathrm{N}_{2}$ molecules on the Co surface.

From the chemisorption data, it can be assumed that the different performances of the $\mathrm{Co} / \mathrm{Mg} / \mathrm{La}$ catalysts were related to the nature of the Co active sites. The different nature of the active sites is most likely attributable to the different crystal structure of cobalt. Two crystalline phases of metallic cobalt, i.e., face-centered cubic (FCC) and hexagonal close packed (HCP) have been described in the literature [43]. Kitakami and Sato et al. [44,45] found that there is a close relationship between the particle size and crystal structure of cobalt. Co fine nanoparticles, synthesized by magnetron sputtering, were reported to consist of pure FCC Co for particles smaller than $20 \mathrm{~nm}$, while the concentration of HCP Co increases significantly with size to ca. $85 \%$ in particles larger than $40 \mathrm{~nm}$. However, the heterogenous catalysts are often very complex solid systems, and e.g., the presence of support, promoter, and thermal pre-treatment method influence the actual crystal structure of the Co active species. Such changes in the crystal structure of metallic cobalt play an important role in the performance of the catalysts $[46,47]$. For example, the effect of the cobalt particle size in Fischer-Tropsch synthesis (FTS) was studied with carbon nanofiber-supported Co catalysts [48]. The results showed that $\mathrm{CO}$ hydrogenation activity was independent of the cobalt particle size with sizes larger than $6 \mathrm{~nm}$, while the activity decreased when the cobalt particle size was smaller. This demonstrated that there was a minimal required cobalt particle size for FTS, i.e., $6 \mathrm{~nm}$, and that was explained by classical structure sensitivity. In the case of the reaction of $\mathrm{NH}_{3}$ synthesis, Rambeau et al. [49] indicated that the rate of $\mathrm{N}_{2}$ chemisorption and equilibrium constants of $\mathrm{H}_{2}$ chemisorption and of hydrogenation of $\mathrm{N}_{\mathrm{ads}}$ were sensitive to the crystal structure of cobalt. It affects the $\mathrm{NH}_{3}$ synthesis rate and clearly means that ammonia synthesis is a structure-sensitive reaction on metallic cobalt. HCP Co exhibits higher activity, $0.0008 \mathrm{~s}^{-1}$, which is two times that of FCC Co, $0.0004 \mathrm{~s}^{-1}$ [25]. These results are in agreement with computational studies. Based on a first-principles kinetic study, involving DFT calculations, Zhang et al. [41] showed that HCP Co displayed higher activity than FCC Co for nitrogen molecule dissociation and thus for ammonia synthesis. The origin of the higher activity of HCP Co resulted from the higher intrinsic activity and high density of the favorable active sites on HCP Co that were not available for FCC Co (due to their distinct crystal structures and morphologies) [40,50]. The reports focusing on the hydrogen chemisorption of $\mathrm{Co}$ [50-58] showed that the adsorption strength of $\mathrm{H}$ atoms on the Co surface depends on its crystal structure.

Thus, regarding prior results from the literature, we deduced that the reduction of the $\mathrm{Co} / \mathrm{Mg} / \mathrm{La}$ precursor prepared by air calcination resulted in the larger Co nanoparticles of the crystal structure, which were different than those produced from the reduction of the respective dried precursor. This was because Co oxide agglomerated into the larger particles (aggregates) during the high-temperature calcination due to sintering. The Co nanoparticles produced upon the reduction of these Co oxide species were larger than those produced from the direct reduction of the precipitated Co species (Table 2). Thus, these cobalt particles $\left(>10 \mathrm{~nm}\right.$ ) could have played an important role in tuning the $\mathrm{NH}_{3}$ synthesis rate, while the small nanoparticles $(<10 \mathrm{~nm})$ were not appropriate. This is because the larger Co nanoparticles are reported to consist of a mixture of FCC and HCP Co phases, while the small Co nanoparticles consist of pure FCC Co phase $[45,46]$. As it was pointed out, the HCP Co phase gives rise to the various favorable active sites with lower nitrogen and hydrogen dissociation barriers, resulting in the superior activity of the catalyst in $\mathrm{NH}_{3}$ synthesis. Therefore, it was reasonable to deduce that the calcined $\mathrm{Co} / \mathrm{Mg} / \mathrm{La}$ was composed of metallic $\mathrm{Co}$, involving mainly an HCP structure, coexisting with a minor 
portion of FCC structure. However, despite the confirmation that the calcined catalyst had the larger Co nanoparticles than that of the non-calcined catalyst (Table 2), the actual crystal structure of these Co nanoparticles was unable to detect (Figure 2).

\section{Materials and Methods}

\subsection{Catalysts Synthesis}

All chemicals used were p.a. grade from POCH company. The $\mathrm{Co} / \mathrm{Mg} / \mathrm{La}$ catalyst precursors were prepared using a co-precipitation method. An aqueous solution of $\mathrm{Co}^{2+}$, $\mathrm{Mg}^{2+}$, and $\mathrm{La}^{3+}$ nitrates was used while maintaining a $\mathrm{Mg} / \mathrm{La}$ molar ratio of 7 and the Co percentage of ca. $10 \mathrm{wt} \%$. During the co-precipitation, the solution of $\mathrm{KOH}$ and $\mathrm{K}_{2} \mathrm{CO}_{3}$ was added dropwise to the nitrates solution under vigorous stirring at $30^{\circ} \mathrm{C}$. The co-precipitation was carried out up to $\mathrm{pH}=11$. The precipitate was kept at $70^{\circ} \mathrm{C}$ for $18 \mathrm{~h}$ for aging, filtered, and washed until free from $\mathrm{NO}_{3}{ }^{-}, \mathrm{CO}_{3}{ }^{2-}, \mathrm{OH}^{-}$, and $\mathrm{K}^{+}$ions. Then, the solid sample was divided into two portions to obtain (1) non-calcined and (2) calcined $\mathrm{Co} / \mathrm{Mg} / \mathrm{La}$ catalyst precursors. The first portion was dried at $120^{\circ} \mathrm{C}$ for $18 \mathrm{~h}$, while the second was dried at $120^{\circ} \mathrm{C}$ for $18 \mathrm{~h}$ and then calcined at $500{ }^{\circ} \mathrm{C}$ for $18 \mathrm{~h}$ in a muffle furnace. Finally, the catalyst precursors were pressed into the cylindrical pellets, crushed, and sieved to the particle size between 0.2 and $0.63 \mathrm{~mm}$.

\subsection{Characterization Studies}

The specific surface area $\left(\mathrm{S}_{\mathrm{BET}}\right)$, total pore volume $\left(\mathrm{V}_{\mathrm{p}}\right)$, and average pore diameter $(\Phi)$ of the prepared materials were evaluated by the $\mathrm{N}_{2}$ physisorption method on the ASAP2020 (Micromeritics) at $-196{ }^{\circ} \mathrm{C}$. Before analysis, the catalyst precursors of $0.5 \mathrm{~g}$ were degassed under vacuum for $1 \mathrm{~h}$ at $50{ }^{\circ} \mathrm{C}$ and the next $4 \mathrm{~h}$ at $80^{\circ} \mathrm{C}$. The results of the measurements were approximated by the Brunauer-Emmett-Teller (BET) and Barrett-Joyner-Halenda $(\mathrm{BJH})$ adsorption isotherm models to determine the $\mathrm{S}_{\mathrm{BET}}, \mathrm{V}_{\mathrm{p}}$, and $\Phi$. For determining the $\mathrm{S}_{\mathrm{BET}}, \mathrm{V}_{\mathrm{p}}$, and $\Phi$ of the catalysts after treatment in hydrogen atmosphere, the precursors of $0.5 \mathrm{~g}$ were subjected to the in situ reduction process in the ASAP 2020 instrument using $\mathrm{H}_{2}$ flow at temperature of $550^{\circ} \mathrm{C}$ for $18 \mathrm{~h}$. Then, the samples were degassed under vacuum for $2 \mathrm{~h}$ at $150{ }^{\circ} \mathrm{C}$, and $\mathrm{N}_{2}$ physisorption measurements were performed. The experimental uncertainty in the $\mathrm{S}_{\mathrm{BET}}, \mathrm{V}_{\mathrm{p}}$, and $\Phi$ was $\pm 1 \%$.

$\mathrm{H}_{2}$-TPR experiments were performed using a thermogravimetric analyzer (TGA, NETZSCH STA449C) integrated with a quadrupole mass spectrometer NETZSCH QMS Aëolos 403C (QMS; m/e range between 10 and 300). A catalyst precursor sample of $0.03 \mathrm{~g}$ was loaded into alumina plates and heated up to $600{ }^{\circ} \mathrm{C}$ at a ramping rate of $5{ }^{\circ} \mathrm{C} \mathrm{min}-1$ under $50 \mathrm{vol} \% \mathrm{H}_{2} /$ Ar mixture flow of $100 \mathrm{~cm}^{3} \mathrm{~min}^{-1}$.

Powder X-ray diffraction patterns were recorded at room temperature on a Bruker D8 Advance diffractometer equipped with a LYNXEYE position sensitive detector, using $\mathrm{Cu}-\mathrm{K} \alpha$ radiation $(\lambda=0.15418 \mathrm{~nm})$. The data were collected in the Bragg-Brentano $(\theta / \theta)$ horizontal geometry (flat reflection mode) between $10^{\circ}$ and $70^{\circ}(2 \theta)$ in a continuous scan using $0.03^{\circ}$ steps $10 \mathrm{~s} / \mathrm{step}$. The diffractometer incident beam path was equipped with a $2.5^{\circ}$ Soller slit and a $1.14^{\circ}$ fixed divergence slit, while the diffracted beam path was equipped with a programmable antiscatter slit (fixed at $2.20^{\circ}$ ), a $\mathrm{Ni} \beta$-filter, and a $2.5^{\circ}$ Soller slit. Data were collected under standard laboratory conditions (temperature and relative humidity). Using the Scherrer equation $(\mathrm{k}=0.89)$, the average crystallite sizes of respective phases were calculated.

Molecular changes of the cobalt catalysts' structure were determined by DRIFT spectroscopy using a Thermo FTIR iS10 spectrometer equipped with an MCT detector and DRIFT High-Temperature Reaction Chamber (Harrick Scientific Co.). The DRIFT analyses were performed by averaging 128 scans with $4 \mathrm{~cm}^{-1}$ resolution. The DRIFT spectra of the catalyst precursors were performed under $50 \mathrm{~cm}^{3} \mathrm{~min}^{-1}$ in the Ar flow at ambient conditions. The in situ reduction of the catalyst precursors was performed under $50 \mathrm{~cm}^{3} \mathrm{~min}^{-1}$ in the $5 \mathrm{vol} \% \mathrm{H}_{2} / \mathrm{N}_{2}$ mixture at $550{ }^{\circ} \mathrm{C}$ for $3 \mathrm{~h}$; then, the temperature was subsequently 
decreased to $150{ }^{\circ} \mathrm{C}$, and the spectra of the reduced catalysts were taken under dehydrated conditions at $150{ }^{\circ} \mathrm{C}$ in a $50 \mathrm{~cm}^{3} \mathrm{~min}^{-1}$ in the Ar flow.

The SEM micrographs and EDS maps of the samples were acquired by using the Field Emission Scanning Electron Microscope (FE-SEM) (FEI Nova NanoSEM 230) equipped with an EDX spectrometer (EDAX Genesis XM4). The samples were dispersed in alcohol; then, a drop was placed on the carbon stub. In the SEM, the samples were analyzed by electron beam at a low accelerating voltage of $5.0 \mathrm{kV}$ using a secondary electron detector. The SEM images were recorded in a beam deceleration mode in order to show more detailed morphological features of the studied materials. In SEM-EDS measurements, the samples were scanned at $18.0 \mathrm{kV}$ using EDAX Apollo X Silicon Drift Detector (SDD).

The TEM micrographs of the samples were performed by using the Transmission Electron Microscopy JEOL 2100HT and TVIPS camera. Before screening, the samples were put on copper 300 mesh grids covered with formvar/carbon film.

$\mathrm{CO}_{2}$-TPD measurements were carried out using an AutoChem II 2920 (Micromeritics) chemisorption analyzer. Prior to the experiment, the catalyst precursor sample of $0.5 \mathrm{~g}$ was loaded into a U-shape quartz reactor and reduced at $550{ }^{\circ} \mathrm{C}$ at a ramping rate of $10{ }^{\circ} \mathrm{C} \mathrm{min}{ }^{-1}$ for $18 \mathrm{~h}$ in the $\mathrm{H}_{2}$ flow $\left(40 \mathrm{~cm}^{3} \mathrm{~min}^{-1}\right)$. Next, the gas flow was switched to helium for purging at $570{ }^{\circ} \mathrm{C}$ for $1 \mathrm{~h}$. The $\mathrm{CO}_{2}$ adsorption was carried out at $40{ }^{\circ} \mathrm{C}$ for $2 \mathrm{~h}$. Then, the sample was rinsed with helium at $40{ }^{\circ} \mathrm{C}$ for $1 \mathrm{~h}$ to remove physisorbed carbon dioxide. The $\mathrm{CO}_{2}$-TPD was carried out in the helium flow $\left(40 \mathrm{~cm}^{3} \mathrm{~min}^{-1}\right)$ at a ramping rate of $5{ }^{\circ} \mathrm{C} \mathrm{min}-1$ up to $900{ }^{\circ} \mathrm{C}$. The outlet gas was analyzed by a thermal conductivity detector (TCD). The uncertainty in the carbon dioxide uptake was $\pm 3 \%$.

$\mathrm{H}_{2}$-TPD measurements were carried out using the same AutoChem II 2920 chemisorption analyzer. Prior to the experiment, the catalyst precursor sample of $0.5 \mathrm{~g}$ was loaded into a U-shape quartz reactor and reduced at $550{ }^{\circ} \mathrm{C}$ at a ramping rate of $10{ }^{\circ} \mathrm{C} \mathrm{min}^{-1}$ for $18 \mathrm{~h}$ in the $\mathrm{H}_{2}$ flow $\left(40 \mathrm{~cm}^{3} \mathrm{~min}^{-1}\right)$. Next, the gas flow was switched to argon for purging at $570{ }^{\circ} \mathrm{C}$ for $1 \mathrm{~h}$. The $\mathrm{H}_{2}$ adsorption was carried out at $150^{\circ} \mathrm{C}$ for $15 \mathrm{~min}$, and it was continued when cooling to $0{ }^{\circ} \mathrm{C}$ and left for a further $15 \mathrm{~min}$ at $0{ }^{\circ} \mathrm{C}$. Then, the sample was rinsed with argon at $0{ }^{\circ} \mathrm{C}$ for $1 \mathrm{~h}$ to remove physisorbed hydrogen. The $\mathrm{H}_{2}$-TPD was carried out in the argon flow $\left(40 \mathrm{~cm}^{3} \mathrm{~min}^{-1}\right)$ at a ramping rate of $5^{\circ} \mathrm{C} \mathrm{min}-1$ up to $900{ }^{\circ} \mathrm{C}$. The outlet gas was analyzed by a thermal conductivity detector (TCD). Based on the hydrogen uptake, the cobalt dispersion (i.e., fraction exposed, $\mathrm{FE})$ and its average particle size $\left(\mathrm{d}_{\mathrm{H}_{2}}\right)$ were calculated $[59,60]$. The uncertainty in the hydrogen uptake was $\pm 3 \%$, and the uncertainty in the cobalt dispersion and its average particle size was $\pm 3 \%$.

$\mathrm{N}_{2}$-TPD measurements were carried out using the same AutoChem II 2920 chemisorption analyzer. Prior to the experiment, the catalyst precursor sample of $0.5 \mathrm{~g}$ was loaded into a U-shape quartz reactor and reduced at $550{ }^{\circ} \mathrm{C}$ at a ramping rate of $10{ }^{\circ} \mathrm{C} \mathrm{min}-1$ for $18 \mathrm{~h}$ in the $\mathrm{H}_{2}$ flow $\left(40 \mathrm{~cm}^{3} \mathrm{~min}^{-1}\right)$. Next, the gas flow was switched to argon for purging at $570{ }^{\circ} \mathrm{C}$ for $1 \mathrm{~h}$. The $\mathrm{N}_{2}$ adsorption was carried out at $200^{\circ} \mathrm{C}$ for $14 \mathrm{~h}$, and it was continued when cooling to $0{ }^{\circ} \mathrm{C}$. Then, the sample was rinsed with helium at $0{ }^{\circ} \mathrm{C}$ for $1 \mathrm{~h}$ to remove physisorbed nitrogen. Furthermore, the temperature was increased from 0 to $900{ }^{\circ} \mathrm{C}$ at a ramping rate of $5^{\circ} \mathrm{C} \mathrm{min}^{-1}$ in the helium flow $\left(40 \mathrm{~cm}^{3} \mathrm{~min}^{-1}\right)$. The outlet gas was monitored by a thermal conductivity detector (TCD). The uncertainty in the nitrogen uptake was $\pm 3 \%$.

\subsection{Catalytic Activity Studies}

Catalytic activity measurements in ammonia synthesis were performed in the flow tubular reactor, as described previously [6-8]. The catalyst precursors of mass $0.5 \mathrm{~g}$ (particle size, $0.2-0.63 \mathrm{~mm}$ ) were activated in the synthesis gas at a flow rate of $30 \mathrm{dm}^{3}$ $\mathrm{h}^{-1}\left(\mathrm{H}_{2} / \mathrm{N}_{2}=3\right.$, purity $\left.99.99995 \mathrm{vol} \%\right)$ at a pressure of $0.1 \mathrm{MPa}$ at different temperatures, i.e., $470{ }^{\circ} \mathrm{C}(72 \mathrm{~h}) \rightarrow 520{ }^{\circ} \mathrm{C}(24 \mathrm{~h}) \rightarrow 550{ }^{\circ} \mathrm{C}(48 \mathrm{~h})$. Under steady-state conditions of pressure $(6.3 \mathrm{MPa})$, temperature $\left(470 / 430 / 400{ }^{\circ} \mathrm{C}\right)$, and gas flow rate $\left(70 \mathrm{dm}^{3} \mathrm{~h}^{-1}\right)$, the ammonia concentration in the outlet gas was measured interferometrically, and then, the $\mathrm{NH}_{3}$ production rate and $\mathrm{H}_{2}$ conversion were determined. After the activity measurements, 
the catalysts were overheated at $600{ }^{\circ} \mathrm{C}$ for $72 \mathrm{~h}$ in the $3 \mathrm{H}_{2}+\mathrm{N}_{2}$ gas mixture $\left(30 \mathrm{dm}^{3} \mathrm{~h}^{-1}\right)$ at $0.1 \mathrm{MPa}$, and the activity was measured again $\left(470{ }^{\circ} \mathrm{C}, 6.3 \mathrm{MPa}, \mathrm{H}_{2} / \mathrm{N}_{2}=3,70 \mathrm{dm}^{3} \mathrm{~h}^{-1}\right)$. The uncertainty in the $\mathrm{NH}_{3}$ production rate was $\pm 1 \%$. The detailed calculation equations can be found in our previous paper $[6-8,21,61]$.

\section{Conclusions}

The influence of the calcination process on the physicochemical properties (e.g., the textural, structural, and basic properties) and catalytic behavior of the $\mathrm{Co} / \mathrm{Mg} / \mathrm{La}$ catalysts for ammonia synthesis have been investigated. The application of the conventional calcination method prior to the activation resulted in the decrease of the BET surface area, pore volume, and the increase of the surface basicity of the catalyst and the particle size of metallic cobalt. This had a substantial effect on the chemisorption properties and nature of the Co active sites, and thus, it affected the activity for ammonia synthesis. The most favorable catalytic performance was achieved with the $\mathrm{Co} / \mathrm{Mg} / \mathrm{La}$ catalyst prepared by the air calcination method. This catalyst was over twice more active than the corresponding non-calcined catalyst at all the reaction conditions tested. The superior performance of this catalyst was attributable to the following:

(1) Strong basicity,

(2) More availability of the Co active sites under the reaction conditions, and

(3) Competitive adsorption between the $\mathrm{H}_{2}$ and $\mathrm{N}_{2}$ molecules.

These findings emphasize the essential role of the materials synthesis procedure in the designing of better, stable catalysts with maximum mass-specific reactivity.

Supplementary Materials: The following are available online at https: / www.mdpi.com/article / 10.3390 / catal11080941/s1, Figure S1: $\mathrm{N}_{2}$ adsorption-desorption isotherms (left) and pore size distribution curves (right) of the calcined (-) and non-calcined (-) Co/Mg/La catalysts in the precursor and reduced forms, Figure S2: SEM micrographs and EDS maps of the Co, Mg, and La elements of the $\mathrm{Co} / \mathrm{Mg} / \mathrm{La}$ catalysts in the reduced form, Table S1: Catalytic activity of the Co/Mg/La catalysts in $\mathrm{NH}_{3}$ synthesis, Table S2: Average crystallite sizes of the respective phases presented of the $\mathrm{Co} / \mathrm{Mg} / \mathrm{La}$ catalysts in the precursor and reduced forms, Table S3: EDS analysis of the selected areas (see Figure S2) of the $\mathrm{Co} / \mathrm{Mg} / \mathrm{La}$ catalysts in the reduced form.

Author Contributions: Conceptualization, H.R.; methodology, H.R. and M.Z.; validation, H.R. and M.Z.; formal analysis, H.R.; investigation, H.R., M.Z., W.P., A.O., P.J., D.S., L.K. and W.R.-P.; resources, W.R.-P.; data curation, H.R.; writing—original draft preparation, H.R., M.Z., D.S. and L.K.; writingreview and editing, H.R., M.Z., P.J., D.S., L.K.; visualization, H.R.; supervision, H.R., M.Z. and W.R.-P.; project administration, H.R.; funding acquisition, W.R.-P. All authors have read and agreed to the published version of the manuscript.

Funding: This research received no external funding.

Data Availability Statement: All data is available within the paper and Supplementary Materials.

Conflicts of Interest: The authors declare no conflict of interest.

\section{References}

1. Keane, M.A. Ceramics for catalysis. J. Mater. Sci. 2003, 38, 4661-4675. [CrossRef]

2. Ogura, Y.; Sato, K.; Miyahara, S.I.; Kawano, Y.; Toriyama, T.; Yamamoto, T.; Matsumura, S.; Hosokawa, S.; Nagaoka, K. Efficient ammonia synthesis over a $\mathrm{Ru} / \mathrm{La}_{0.5} \mathrm{Ce}_{0.5} \mathrm{O}_{1.75}$ catalyst pre-reduced at high temperature. Chem. Sci. 2018, 9, 2230-2237. [CrossRef] [PubMed]

3. Ogura, Y.; Tsujimaru, K.; Sato, K.; Miyahara, S.I.; Toriyama, T.; Yamamoto, T.; Matsumura, S.; Nagaoka, K. Ru/La ${ }_{0.5} \mathrm{Pr}_{0.5} \mathrm{O}_{1.75}$ Catalyst for Low-Temperature Ammonia Synthesis. ACS Sustain. Chem. Eng. 2018, 6, 17258-17266. [CrossRef]

4. Gao, W.; Wang, P.; Guo, J.; Chang, F.; He, T.; Wang, Q.; Wu, G.; Chen, P. Barium Hydride-Mediated Nitrogen Transfer and Hydrogenation for Ammonia Synthesis: A Case Study of Cobalt. ACS Catal. 2017, 7, 3654-3661. [CrossRef]

5. Wang, X.; Li, L.; Zhang, T.; Lin, B.; Ni, J.; Au, C.T.; Jiang, L. Strong metal-support interactions of Co-based catalysts facilitated by dopamine for highly efficient ammonia synthesis: In situ XPS and XAFS spectroscopy coupled with TPD studies. Chem. Commun. 2019, 55, 474-477. [CrossRef] [PubMed] 
6. Kowalczyk, Z.; Jodzis, S.; Sentek, J. Studies on kinetics of ammonia synthesis over ruthenium catalyst supported on active carbon. Appl. Catal. A Gen. 1996, 138, 83-91. [CrossRef]

7. Kowalczyk, Z.; Sentek, J.; Jodzis, S.; Muhler, M.; Hinrichsen, O. Effect of potassium on the kinetics of ammonia synthesis and decomposition over fused iron catalyst at atmospheric pressure. J. Catal. 1997, 169, 407-414. [CrossRef]

8. Kowalczyk, Z. Effect of potassium on the high pressure kinetics of ammonia synthesis over fused iron catalyst. Catal. Lett. 1996, 37, 173-179. [CrossRef]

9. Jacobsen, C.J.H. Boron nitride: A novel support for ruthenium-based ammonia synthesis catalysts. J. Catal. 2001, 200, 1-3. [CrossRef]

10. Imamura, K.; Miyahara, S.; Kawano, Y.; Sato, K.; Nakasaka, Y.; Nagaoka, K. Kinetics of ammonia synthesis over Ru/Pr $2 \mathrm{O}_{3}$. J. Taiwan Inst. Chem. Eng. 2019, 105, 50-56. [CrossRef]

11. Li, W.; Wang, S.; Li, J. Highly Effective $\mathrm{Ru} / \mathrm{BaCeO}_{3}$ Catalysts on Supports with Strong Basic Sites for Ammonia Synthesis. Chem. Asian J. 2019, 14, 2815-2821.

12. Cai, J.; Wang, C.; Liu, Y.; Ni, J.; Lin, B.; Wang, X.; Lin, J.; Jiang, L. Effect of pore-size distribution on Ru/ZSM-5 catalyst for enhanced $\mathrm{N}_{2}$ activation to ammonia via dissociative mechanism. J. Rare Earths 2020, 38, 873-882. [CrossRef]

13. Miyahara, S.; Sato, K.; Kawano, Y.; Imamura, K.; Ogura, Y.; Tsujimaru, K.; Nagaoka, K. Ammonia synthesis over lanthanoid oxide-supported ruthenium catalysts. Catal. Today 2021, 376, 36-40. [CrossRef]

14. Zhang, L.; Lin, J.; Ni, J.; Wang, R.; Wei, K. Highly efficient $\mathrm{Ru} / \mathrm{Sm}_{2} \mathrm{O}_{3}-\mathrm{CeO}_{2}$ catalyst for ammonia synthesis. Catal. Commun. 2011, 15, 23-26. [CrossRef]

15. Wang, Z.Q.; Ma, Y.C.; Lin, J.X. Ruthenium catalyst supported on high-surface-area basic $\mathrm{ZrO}_{2}$ for ammonia synthesis. J. Mol. Catal. A Chem. 2013, 378, 307-313. [CrossRef]

16. Luo, X.; Wang, R.; Ni, J.; Lin, J.; Lin, B.; Xu, X.; Wei, K. Effect of $\mathrm{La}_{2} \mathrm{O}_{3}$ on $\mathrm{Ru} / \mathrm{CeO}_{2}-\mathrm{La}_{2} \mathrm{O}_{3}$ catalyst for ammonia synthesis. Catal Lett. 2009, 133, 382-387. [CrossRef]

17. Javaid, R.; Aoki, Y.; Nanba, T. Highly efficient $\mathrm{Ru} / \mathrm{MgO}-\mathrm{Er}_{2} \mathrm{O}_{3}$ catalysts for ammonia synthesis. J. Phys. Chem. Solids 2020, 146, 109570. [CrossRef]

18. Li, W.; Liu, P.; Niu, R.; Li, J.; Wang, S. Influence of $\mathrm{CeO}_{2}$ supports prepared with different precipitants over $\mathrm{Ru} / \mathrm{CeO} 2$ catalysts for ammonia synthesis. Solid State Sci. 2020, 99, 105983. [CrossRef]

19. Lin, B.; Liu, Y.; Heng, L.; Ni, J.; Lin, J.; Jiang, L. Effect of ceria morphology on the catalytic activity of $\mathrm{Co} / \mathrm{CeO} 2$ catalyst for ammonia synthesis. Catal. Commun. 2017, 101, 15-19. [CrossRef]

20. Wang, X.; Ni, J.; Lin, B.; Wang, R.; Lin, J.; Wei, K. Highly efficient Ru/MgO-CeO 2 catalyst for ammonia synthesis. Catal. Commun. 2010, 12, 251-254. [CrossRef]

21. Ronduda, H.; Zybert, M.; Patkowski, W.; Tarka, A.; Ostrowski, A.; Raróg-Pilecka, W. Kinetic studies of ammonia synthesis over a barium-promoted cobalt catalyst supported on magnesium-lanthanum mixed oxide. J. Taiwan Inst. Chem. Eng. 2020, 114, 241-248. [CrossRef]

22. Ronduda, H.; Zybert, M.; Patkowski, W.; Tarka, A.; Ostrowski, A.; Jodłowski, P.; Szymański, D.; Kępiński, L.; Raróg-Pilecka, W. A high performance barium-promoted cobalt catalyst supported on magnesium-lanthanum mixed oxide for ammonia synthesis. RSC Adv. 2021, 11, 14218-14228. [CrossRef]

23. Ronduda, H.; Zybert, M.; Patkowski, W.; Tarka, A.; Jodłowski, P.; Kẹpiński, L.; Sarnecki, A.; Moszyński, D.; Raróg-Pilecka, W. Tuning the catalytic performance of $\mathrm{Co} / \mathrm{Mg}$-La system for ammonia synthesis via the active phase precursor introduction method. Appl. Catal. A Gen. 2020, 598, 117553. [CrossRef]

24. Zybert, M.; Wyszyńska, M.; Tarka, A.; Patkowski, W.; Ronduda, H.; Mierzwa, B.; Kępiński, L.; Sarnecki, A.; Moszyński, D.; Raróg-Pilecka, W. Surface enrichment phenomenon in the Ba-doped cobalt catalyst for ammonia synthesis. Vacuum 2019, 168, 108831. [CrossRef]

25. Thommes, M.; Kaneko, K.; Neimark, A.V.; Olivier, J.P.; Rodriguez-Reinoso, F.; Rouquerol, J.; Sing, K.S.W. Physisorption of gases, with special reference to the evaluation of surface area and pore size distribution (IUPAC Technical Report). Pure Appl. Chem. 2015, 87, 1051-1069. [CrossRef]

26. Yu, Y.; Gan, Y.M.; Huang, C.; Lu, Z.H.; Wang, X.; Zhang, R.; Feng, G. Ni/La $\mathrm{L}_{3}$ and Ni/MgO-La $2 \mathrm{O}_{3}$ catalysts for the decomposition of $\mathrm{NH}_{3}$ into hydrogen. Int. J. Hydrog. Energy 2020, 45, 16528-16539. [CrossRef]

27. Ansari, A.; Ali, A.; Asif, M. Shamsuzzaman Microwave-assisted MgO NP catalyzed one-pot multicomponent synthesis of polysubstituted steroidal pyridines. New J. Chem. 2018, 42, 184-197. [CrossRef]

28. Ni, J.; Chen, L.; Lin, J.; Schreyer, M.K.; Wang, Z.; Kawi, S. High performance of Mg-La mixed oxides supported Ni catalysts for dry reforming of methane: The effect of crystal structure. Int. J. Hydrog. Energy 2013, 38, 13631-13642. [CrossRef]

29. Turcotte, R.P.; Sawyer, J.O.; Eyring, L. On the rare earth dioxymonocarbonates and their decomposition. Inorg. Chem. 1969, 8 , 238-246. [CrossRef]

30. Sutradhar, N.; Sinhamahapatra, A.; Pahari, S.K.; Pal, P.; Bajaj, H.C.; Mukhopadhyay, I.; Panda, A.B. Controlled synthesis of different morphologies of MgO and their use as solid base catalysts. J. Phys. Chem. C 2011, 115, 12308-12316. [CrossRef]

31. Tomić-Tucaković, B.; Majstorović, D.; Jelić, D.; Mentus, S. Thermogravimetric study of the kinetics of $\mathrm{Co}_{3} \mathrm{O}_{4} \mathrm{reduction}$ by hydrogen. Thermochim. Acta 2012, 541, 15-24. [CrossRef] 
32. Wang, Z.; Liu, B.; Lin, J. Highly effective perovskite-type $\mathrm{BaZrO}_{3}$ supported $\mathrm{Ru}$ catalyst for ammonia synthesis. Appl. Catal. A Gen. 2013, 458, 130-136. [CrossRef]

33. Sato, K.; Imamura, K.; Kawano, Y.; Miyahara, S.-i.; Yamamoto, T.; Matsumura, S.; Nagaoka, K. A low-crystalline ruthenium nano-layer supported on praseodymium oxide as an active catalyst for ammonia synthesis. Chem. Sci. 2016, 8, 674-679. [CrossRef]

34. Cornu, D.; Guesmi, H.; Krafft, J.M.; Lauron-Pernot, H. Lewis acido-basic interactions between $\mathrm{CO}_{2}$ and $\mathrm{MgO}$ surface: DFT and DRIFT approaches. J. Phys. Chem. C 2012, 116, 6645-6654. [CrossRef]

35. Rosowski, F.; Hornung, A.; Hinrichsen, O.; Herein, D.; Muhler, M.; Ertl, G. Ruthenium catalysts for ammonia synthesis at high pressures: Preparation, characterization, and power-law kinetics. Appl. Catal. A Gen. 1997, 151, 443-460. [CrossRef]

36. Urabe, K.; Aika, K.; Ozaki, A. Activation of nitrogen by alkali metal-promoted transition metal: VI Hydrogen effect on isotopic equilibration of nitrogen and rate-determining step of ammonia synthesis on potassium-promoted ruthenium catalysts. J. Catal. 1976, 42, 197-204. [CrossRef]

37. Muhler, M.; Rosowski, F.; Hinrichsen, O.; Hornung, A.; Ertl, G. Ruthenium as catalyst for ammonia synthesis. Stud. Surf. Sci. Catal. 1996, 101, 317-326.

38. Hinrichsen, O.; Rosowski, F.; Hornung, A.; Muhler, M.; Ertl, G. The Kinetics of Ammonia Synthesis over Ru-Based Catalysts. J. Catal. 1997, 165, 33-44. [CrossRef]

39. Hinrichsen, O.; Rosowski, F.; Muhler, M.; Ertl, G. The microkinetics of ammonia synthesis catalyzed by cesium-promoted supported ruthenium. Chem. Eng. Sci. 1996, 51, 1683-1690. [CrossRef]

40. Zhang, B.Y.; Chen, P.P.; Liu, J.X.; Su, H.Y.; Li, W.X. Influence of Cobalt Crystal Structures on Activation of Nitrogen Molecule: A First-Principles Study. J. Phys. Chem. C 2019, 123, 10956-10966. [CrossRef]

41. Hagen, S.; Barfod, R.; Fehrmann, R.; Jacobsen, C.J.H.; Teunissen, H.T.; Chorkendorff, I. Ammonia synthesis with barium-promoted iron-cobalt alloys supported on carbon. J. Catal. 2003, 214, 327-335. [CrossRef]

42. Kojima, R.; Enomoto, H.; Muhler, M.; Aika, K.I. Cesium-promoted rhenium catalysts supported on alumina for ammonia synthesis. Appl. Catal. A Gen. 2003, 246, 311-322. [CrossRef]

43. Dinega, D.P.; Bawendi, M.G. A solution-phase chemical approach to a new crystal structure of cobalt. Angew. Chem. Int. Ed. 1999, 38, 1788-1791. [CrossRef]

44. Sato, H.; Kitakami, O.; Sakurai, T.; Shimada, Y.; Otani, Y.; Fukamichi, K. Structure and magnetism of hcp-Co fine particles. J. Appl. Phys. 1997, 81, 1858-1862. [CrossRef]

45. Kitakami, O.; Sato, H.; Shimada, Y.; Sato, F.; Tanaka, M. Size effect on the crystal phase of cobalt fine particles. Phys. Rev. B 1997, 56, 13849-13854. [CrossRef]

46. Liu, J.X.; Wang, P.; Xu, W.; Hensen, E.J.M. Particle Size and Crystal Phase Effects in Fischer-Tropsch Catalysts. Engineering 2017, 3, 467-476. [CrossRef]

47. Mehrbod, M.; Martinelli, M.; Martino, A.G.; Cronauer, D.C.; Jeremy Kropf, A.; Marshall, C.L.; Jacobs, G. Fischer-Tropsch synthesis: Direct cobalt nitrate reduction of promoted $\mathrm{Co} / \mathrm{TiO}_{2}$ catalysts. Fuel 2019, 245, 488-504. [CrossRef]

48. Bezemer, G.L.; Bitter, J.H.; Kuipers, H.P.C.E.; Oosterbeek, H.; Holewijn, J.E.; Xu, X.; Kapteijn, F.; Van Diilen, A.J.; De Jong, K.P. Cobalt particle size effects in the Fischer-Tropsch reaction studied with carbon nanofiber supported catalysts. J. Am. Chem. Soc. 2006, 128, 3956-3964. [CrossRef]

49. Rambeau, G.; Jorti, A.; Amariglio, H. Catalytic activity of a cobalt powder in $\mathrm{NH}_{3}$ synthesis in relation with the allotropic transformation of the metal. J. Catal. 1985, 94, 155-165. [CrossRef]

50. Liu, J.X.; Su, H.Y.; Sun, D.P.; Zhang, B.Y.; Li, W.X. Crystallographic dependence of CO activation on cobalt catalysts: HCP versus FCC. J. Am. Chem. Soc. 2013, 135, 16284-16287. [CrossRef]

51. Yu, M.; Liu, L.; Wang, Q.; Jia, L.; Hou, B.; Si, Y.; Li, D.; Zhao, Y. High coverage $\mathrm{H}_{2}$ adsorption and dissociation on fcc Co surfaces from DFT and thermodynamics. Int. J. Hydrog. Energy 2018, 43, 5576-5590. [CrossRef]

52. Chen, Q.; Svenum, I.H.; Gavrilovic, L.; Chen, D.; Blekkan, E.A. Effect of trace potassium on hydrogen adsorption and dissociation on hcp cobalt: A density functional theory study. Surf. Sci. 2019, 681, 24-31. [CrossRef]

53. Lisowski, W. Kinetics and thermodynamics of hydrogen interaction with thin cobalt films. Appl. Surf. Sci. 1989, 35, 399-408. [CrossRef]

54. Wang, Q.; Zhang, R.; Jia, L.; Hou, B.; Li, D.; Wang, B. Insight into the effect of surface coverage and structure over different Co surfaces on the behaviors of $\mathrm{H}_{2}$ adsorption and activation. Int. J. Hydrog. Energy 2016, 41, 23022-23032. [CrossRef]

55. Weststrate, C.J.; Mahmoodinia, M.; Farstad, M.H.; Svenum, I.H.; Strømsheim, M.D.; Niemantsverdriet, J.W.; Venvik, H.J. Interaction of hydrogen with flat (0001) and corrugated (11-20) and (10-12) cobalt surfaces: Insights from experiment and theory. Catal. Today 2020, 342, 124-130. [CrossRef]

56. Van Helden, P.; Van Den Berg, J.A.; Weststrate, C.J. Hydrogen adsorption on co surfaces: A density functional theory and temperature programmed desorption study. ACS Catal. 2012, 2, 1097-1107. [CrossRef]

57. Nakhaei Pour, A.; Keyvanloo, Z.; Izadyar, M.; Modaresi, S.M. Dissociative hydrogen adsorption on the cubic cobalt surfaces: A DFT study. Int. J. Hydrog. Energy 2015, 40, 7064-7071. [CrossRef]

58. Zhou, Y.; Wang, C.; Peng, X.; Zhang, T.; Wang, X.; Jiang, Y.; Qi, H.; Zheng, L.; Lin, J.; Jiang, L. Boosting Efficient Ammonia Synthesis over Atomically Dispersed Co-Based Catalyst via the Modulation of Geometric and Electronic Structures. CCS Chem. 2021, 3, 1881-1892. [CrossRef] 
59. Reuel, R.C.; Bartholomew, C.H. The stoichiometries of $\mathrm{H}_{2}$ and $\mathrm{CO}$ adsorptions on cobalt: Effects of support and preparation. J. Catal. 1984, 85, 63-77. [CrossRef]

60. Borodziński, A.; Bonarowska, M. Relation between crystallite size and dispersion on supported metal catalysts. Langmuir 1997, 13, 5613-5620. [CrossRef]

61. Huang, C.; Yu, Y.; Tang, X.; Liu, Z.; Zhang, J.; Ye, C.; Ye, Y.; Zhang, R. Hydrogen generation by ammonia decomposition over $\mathrm{Co} / \mathrm{CeO}_{2}$ catalyst: Influence of support morphologies. Appl. Surf. Sci. 2020, 532, 147335. [CrossRef] 